\title{
Metal Complexes versus Organocatalysts in Asymmetric 1,3-Dipolar Cycloadditions
}

\author{
Carmen Nájera, José M. Sansano* and Miguel Yus \\ Departamento de Química Orgánica and Instituto de Síntesis Orgánica (ISO), \\ Facultad de Ciencias, Universidad de Alicante, Apdo. 99, E-03080 Alicante, Spain
}

\begin{abstract}
Neste review apresentamos uma comparação entre reações de cicloadição 1,3-dipolar catalizadas por ácido de Lewis com as organo catalizadas, com ênfase na síntese enantiosseletiva de sistemas hetero ou carbocíclicos de cinco membros. Essas reações exibem características interessantes, mas a mais importante é a formação de até quatro centro estereogênicos em apenas uma etapa de reação.
\end{abstract}

In this review, a comparison between the Lewis acid catalysed and organocatalysed 1,3-dipolar cycloaddition is presented with special focus on the enantioselective synthesis of five-membered hetero- or carbocyclic systems, is described. These reactions exhibit very interesting features, but the most important one is the generation of up to four stereogenic centres in only one reaction step.

Keywords: asymmetric catalysis, cycloadditions, Lewis acids, organocatalysts

\section{Introduction}

The synthesis of chiral compounds is an important and challenging area of contemporary synthetic organic chemistry. When the generation of a stereogenic centre involves a carbon-carbon bond formation the transformation becomes fundamental to organic chemistry for the construction of the skeletal framework of simple or complex organic molecules. ${ }^{1}$

Cycloadditions $^{2}$ are one of the best known and most widely used methods for generating carbon-carbon and carbon-heteroatom bonds with extremely high stereocontrol. Particularly, 1,3-dipolar cycloaddition (1,3-DC) is a classic reaction of a 1,3-dipole $\mathbf{I}$ with a dipolarophile II, such as alkenes, alkynes, and molecules possessing related heteroatom functional groups like carbonyl compounds and nitriles (Scheme 1). ${ }^{3}$ In general, yields of five membered heterocycles III are high with a few and easily removable impurities. This reaction is very versatile, allowing the presence of many functional groups in both components. The available precursors of dipole $\mathbf{I}$ can be, basically, divided in two groups: the allyl anion-type Ia, such as nitrones, azomethine ylides, azomethine imines, carbonyl ylides and carbonyl imines,

*e-mail: jmsansano@ua.es

Dedicated to the memory of Prof. Octavio A. C. Antunes
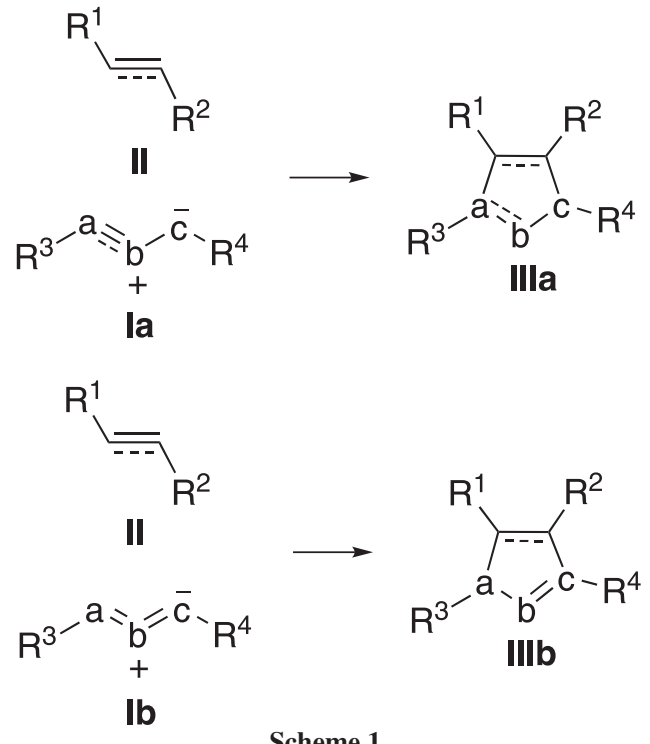

Scheme 1.

and the linear propargyl/allenyl anion-type $\mathbf{I b}$, such as nitrile oxides, nitrile imines, nitrile ylides, diazoalkanes and azides (Figure 1).

From the mechanistic point of view, these $[2 s+4 s]$ additions are stereoconservative (suprafacial) and stereospecific, and the six $\pi$-electrons participate in a concerted (usually in thermally induced 1,3-DCs) or nonconcerted reaction pathway (habitually when a catalyst is employed) controlled by the HOMO-LUMO interaction rules. ${ }^{4}$ The results of this elevated stereocontrol are the 
responsible for the high diastereo- and regioselectivity (and also enantioselectivity in asymmetric synthethic examples) achieved in an impressive number of heterocycles III. Consequently, up to four stereogenic centres can be unambiguously generated in only one reaction step whether a diastereo- or enantioselective approach is performed. In addition, steric effects, originated by the presence of bulky substituents in both reagents, play an important role overriding these secondary electronic interactions affording mixtures of endo- and exo-adducts. The presence of a chiral metal complex or an organocatalyst in these 1,3-DCs can alter both the orbital coefficients of the reacting atoms of each component, lowering the temperature of the process, and favouring a specific transition state. The coordination between the catalyst, the 1,3-dipole, and the dipolarophile, is of crucial importance for the overall regio-, diastereo- and enantioselectivity of the process. ${ }^{4}$

In this review, we will survey and compare the advantages and disadvantages of using chiral metal complexes or chiral organocatalysts in the most relevant examples. These two asymmetric induction tools constitute more than $95 \%$ of publications concerning asymmetric catalysts, and the greatest challenge in discovering new asymmetric catalysts is conducting interdisciplinary research that combines organic, inorganic, organometallic, and biomimetic chemistry. Figures 1 and 2 show the most employed 1,3-dipoles, and the most significant contributions appeared in the literature during the last three years. 1,3-Dipoles such as azomethine ylides, nitrones, diazoalkanes, carbonyl ylides, and nitrile oxides undergo both, metal-catalysed or organocatalysed enantioselective 1,3-DCs. On the other hand, 1,3-dipoles as phosphonium-inner salts can be exclusively generated by reaction of an organocatalyst (chiral phosphane) with alkyl allenoates (Figure 1).

$$
\mathrm{R}_{2} \mathrm{C}=\mathrm{N}_{-}^{\mathrm{N}^{+}} \mathrm{CR}^{1} \mathrm{R}^{3}
$$

Azomethine ylides<smiles>[R2][O+]C=[Pt]</smiles><smiles>[R]C#[N+][O-]</smiles>

Carbonyl ylides Nitrile oxides
Nitrones Diazoalkanes

$$
\overbrace{\mathrm{PR}_{3}} \mathrm{CO}_{2} \mathrm{R}^{1}
$$

$$
\mathrm{R}_{2} \mathrm{C}=\stackrel{+}{\mathrm{N}}=\mathrm{N}^{-}
$$
salt

Figure 1. Most employed 1,3-dipoles in the enantioselective synthesis of heterocycles III.

\section{Azomethine Ylides}

The 1,3-DC using azomethine ylides is only productive when electron-deficient alkenes are employed. Azomethine

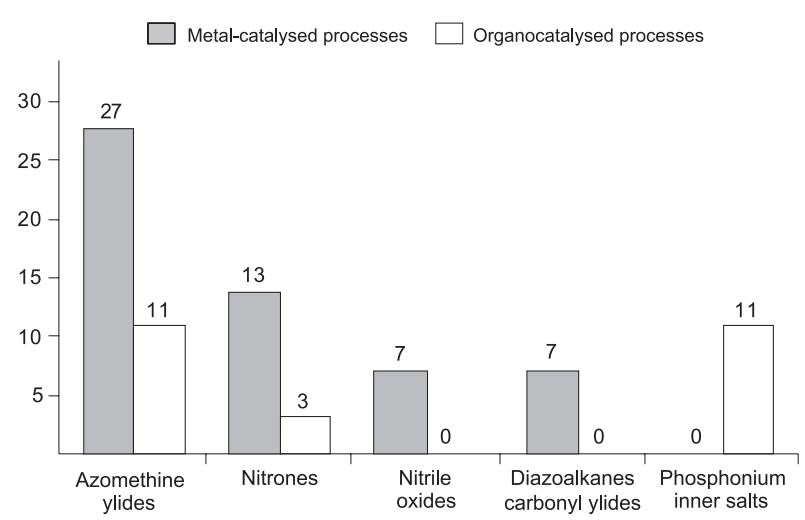

Figure 2. Most relevant contributions published between beginning 2006-first third 2009.

ylides are 1,3-dipoles very frequently generated in situ by a thermal 1,2-prototropy shift in iminoesters $\mathbf{1}$, or by a base-assisted formation of a metallo-dipole. ${ }^{3,5}$ Although many other methods are known, the metallo-dipole route is the most employed due to its simplicity and the mildness of the required reaction conditions. According to the stereochemical point of view, metallo-dipoles $\mathbf{3}$ are crucial species because their geometry is perfectly controlled, so allowing the attainment of high diastereoselectivity of 1,5-cis-adducts. As it was outlined before, the endo:exo diastereoselections achieved in the preparation of proline derivatives $4^{6}$ (Scheme 2 ), are clearly dependant on the metal employed as cocatalyst. For the particular case of electron deficient alkenes $\left[\mathrm{R}^{1}\right.$ and/or $\mathrm{R}^{2}=$ electron-withdrawing group (EWG)], the frontier molecular orbital interactions involved can also be referred to as either exo- or endo-, where the endo-transition state is stabilised by small electronic interactions [that means that the EWG is oriented to the 1,3-dipole orbitals] or via an exo-transition state lacking such stabilisation (on this occasion the EWG is oriented far away from the 1,3-dipole). All these features are a solid support for developing catalytic enantioselective processes ${ }^{3,5}$ generating unambiguously the absolute configuration of up to four stereogenic centres of pyrrolidines 4 .

The asymmetric 1,3-DC of azomethine ylides and alkenes was pioneered by Grigg and co-workers ${ }^{7}$ in 1991 using stoichiometric amounts of chiral bases or chiral metal complexes. However, it was just in 2002 when the first substoichiometric catalytic ( $3 \mathrm{~mol} \%$ ) enantioselective transformation was successfully reported by Zhang and co-workers ${ }^{8}$ using a chiral diphosphane/silver(I) complex. At that time, this cycloaddition became a fascinating transformation and many contributions appeared with outstanding results. ${ }^{5}$ Chiral metal complexes, chiral bases, and chiral organocatalysts have all given excellent results, in terms of diastereo- and enantioselectivities, and wider general scope when chiral metallodipoles were generated 


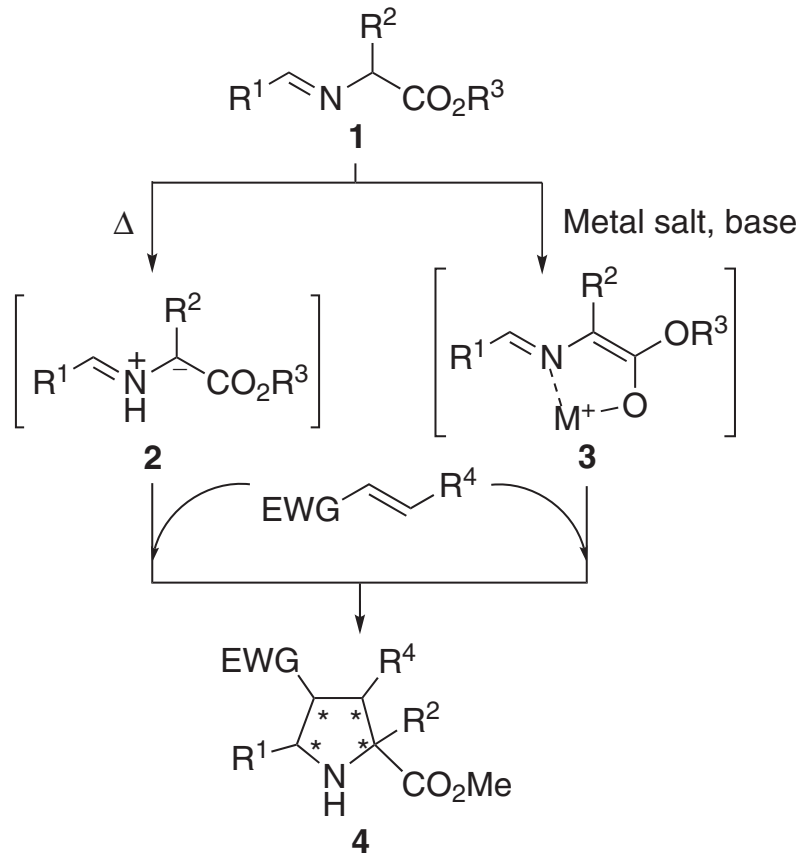

Scheme 2. General 1,3-DC using azomethine ylides. as intermediates. Based on the previous results obtained with silver(I $)^{9}$ and copper(I),${ }^{10}$ several complexes afforded catalytically the most efficient and attractive processes.

The metal catalysed reaction depicted in Scheme 3 can be efficiently promoted by all the reported chiral metal complexes. For example, chiral silver complexes (Figure 3) catalysed diastereoselectively the 1,3-DC affording endocycloadducts $\mathbf{6}$ in very good yields under different reaction conditions. In all cases, the silver catalysts were formed by direct mixing of the chiral ligand and the corresponding silver(I) salt.

Concerning the most useful dipolarophile, the complex formed by $\left(S, R_{\mathrm{p}}\right)-\mathbf{8} \mathbf{a}$ and $\mathrm{AgOAc}$ catalysed the reaction of methyl arylideneglycinates $5\left(\mathrm{R}^{1}=\mathrm{H}, \mathrm{R}^{2}=\mathrm{Me}\right)$ with $\mathrm{N}$-phenylmaleimide (NPM), in the absence of a base in diethyl ether at $0{ }^{\circ} \mathrm{C}$. The major product ent-endo-6 was selectively obtained, after 2-4 h, in excellent chemical yields (95-98\%) and very good enantioselectivities (86$93 \%$ ee $).{ }^{11}$ A very small modification in the substituent of the arylic fragment of the thioether group in $\left(S, R_{\mathrm{p}}\right)-\mathbf{8 a}$,

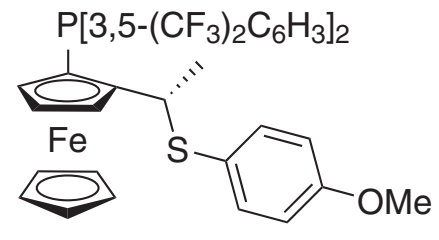

$\left(S, R_{p}\right)-8 \mathbf{a} / \mathrm{AgOAC}$

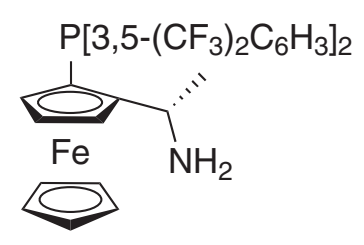

$\left(S, R_{\mathrm{p}}\right)-\mathbf{8 d} / \mathrm{AgOAC}$<smiles>C[C@H](c1ccccc1)N([C@H](C)c1ccccc1)P(Oc1ccc2ccccc2c1-c1cccc2ccccc12)c1ccccc1</smiles>

$\left(S_{\mathrm{a}}, R, R\right)-11 / \mathrm{AgClO}_{4}$

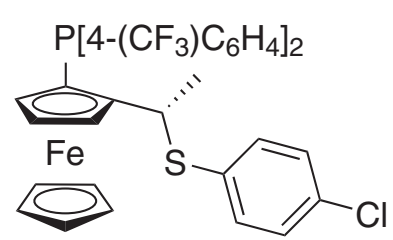

$\left(S, R_{p}\right)-8 \mathrm{~b} / \mathrm{AgOAc}$<smiles>Pc1cccc(-c2c(P)ccc3ccccc23)c1-c1ccccc1</smiles>

(S)-Binap $9 / \mathrm{AgClO}_{4}$

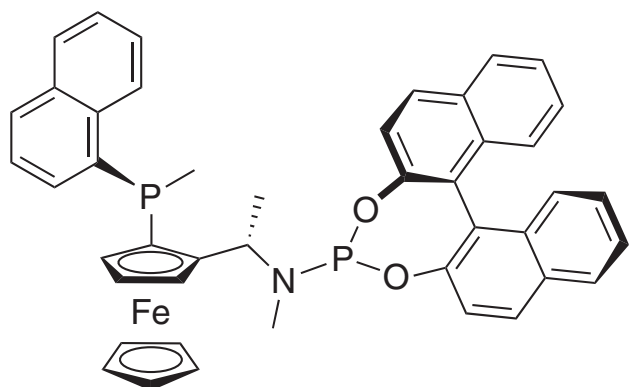

12 / AgOAc

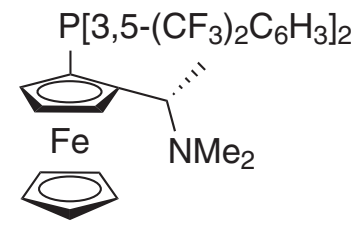

$\left(S, R_{p}\right)-8 \mathrm{c} / \mathrm{AgOAc}$<smiles>CN(C)p1oc2ccc3ccccc3c2c2c(ccc3ccccc32)o1</smiles>

(S)-Monophos $10 / \mathrm{AgClO}_{4}$<smiles>Nc1c(Br)c(C(F)(F)F)cc(C(F)(F)F)c1-c1c(C(F)(F)F)cc(C(F)(F)F)c(Br)c1NPc1ccccc1</smiles>

(S)-13 / AgOAc

Figure 3. Chiral ligands/silver salts used to generate chiral Lewis acids employed in the enantioselective 1,3-DC of azomethine ylides 5 and dipolarophiles. 
Dipolarophile<smiles>C=COCC</smiles><smiles>[R]OC(=O)/N=C/[3H]</smiles>

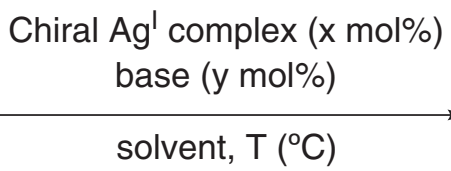

Minor or non-detected exo-diastereoisomers

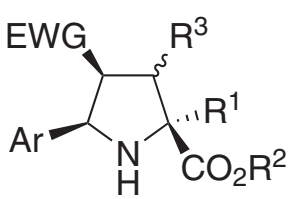

endo-cycloadduct 6

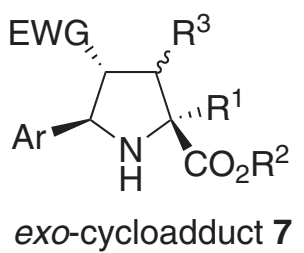

or<smiles>[R]OC(=O)C1([R])N[C@H]([Al])[C@@H](C(C)C)[C@H]1[R]</smiles>

ent-6-endo-cycloadduct

or

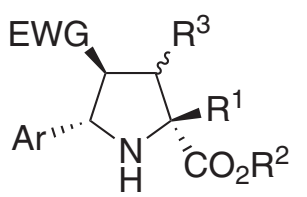

ent-7-exo-cycloadduct

Scheme 3. Model reaction for chiral silver(I) complex catalysed 1,3-DCs.

to give ligand $\left(S, R_{\mathrm{p}}\right)-\mathbf{8 b}$, was enough to accomplish, in identical chemical yields, good enantioselectivities of the corresponding ent-endo-compounds $\mathbf{6}$, when methyl maleate was allowed to react with iminoesters $5\left(R^{1}=\mathrm{H}\right.$, $\left.\mathrm{R}^{2}=\mathrm{Me}\right)$. In this last example, the temperature required was $-25^{\circ} \mathrm{C}$ and the reaction was completed in $3 \mathrm{~h} .{ }^{11}$

The same group further demonstrated how simple hydrogen bonding is enough to invert the enantioselection of the process. The employed ligands were slightly different chiral ferrocenes $\left(S, R_{\mathrm{p}}\right)-\mathbf{8 c}$ and $\mathbf{8 d}$, which were combined with AgOAc. In the reaction of the 1,3-dipole precursor 5 with dimethyl maleate, the proposed variation of the transition states TS-14 and TS-15, supported as well by a computational study, is shown in Scheme 4. The carbonyl groups of the dipolarophile can be coordinated by the $\mathrm{Ag}$ cation of the $\left(S, R_{\mathrm{p}}\right)-\mathbf{8 d}-\mathrm{AgOAc}$ complex and may form two hydrogen bonding interactions with the $\mathrm{NH}_{2}$ group (TS-15). However, the dimethylamino group of the complex $\left(S, R_{\mathrm{p}}\right)-\mathbf{8 c}-\mathrm{AgOAc}$ cannot form these hydrogen bondings and the methyl groups would cause steric repulsion in TS-14. The two different approaches proposed could explain the opposite facial enantiodiscrimination observed experimentally. Thus, when the $p$-chlorobenzaldehyde imine 5 was allowed to react with dimethyl maleate it was deduced that the absence of the hydrogen bondings in TS-14 $\left[\left(S, R_{\mathrm{p}}\right)-\mathbf{8 c}-\mathrm{AgOAc}\right.$ complex] would give the pyrrolidine ent-endo-6 (92\% ee and > 98:2 endo:exo ratio, Scheme 4), whilst the TS-15 [(S, $\left.R_{\mathrm{P}}\right)-\mathbf{8 d}-\mathrm{AgOAc}$ complex $]$

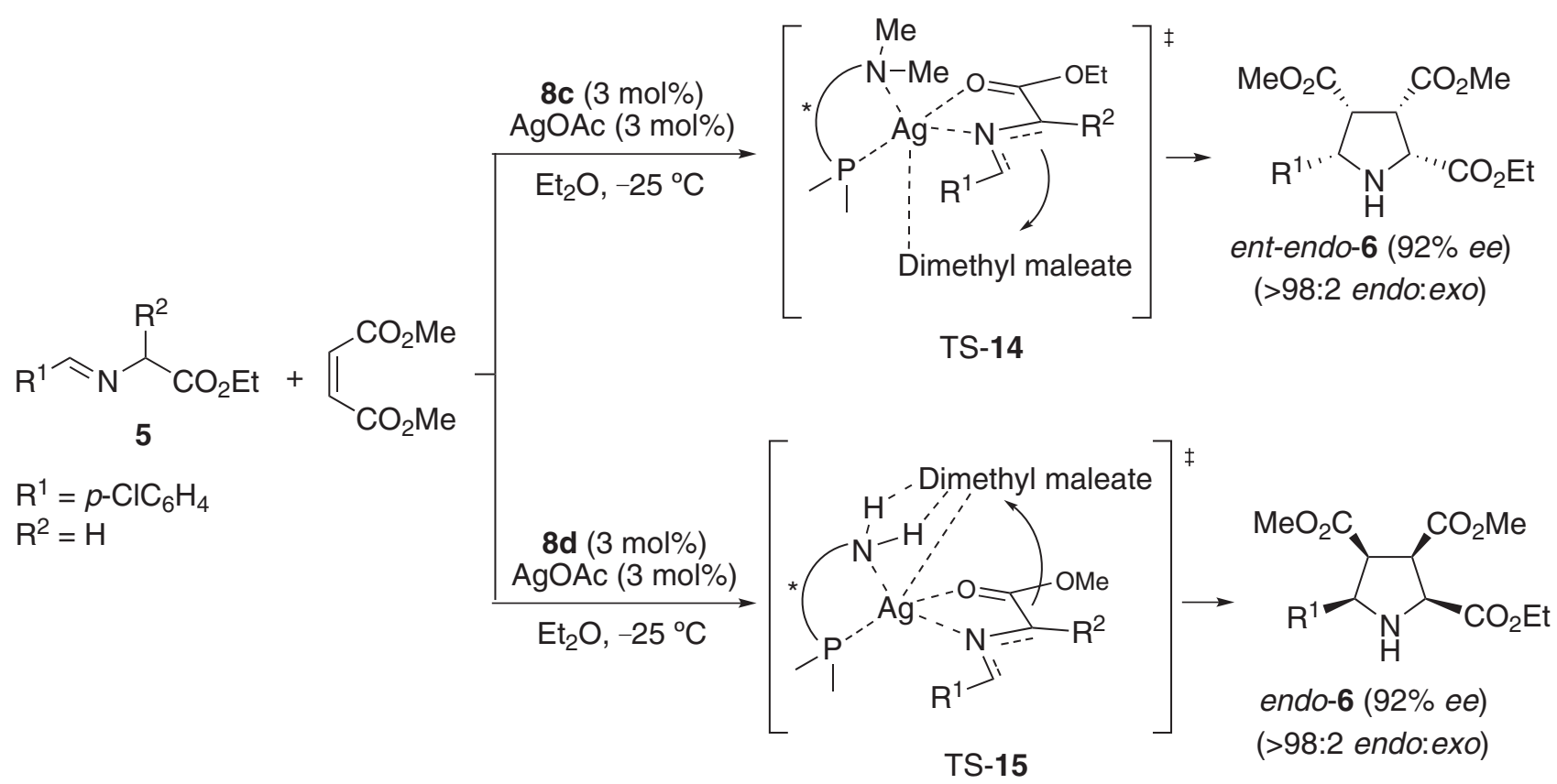

Scheme 4. 
would generate the corresponding adduct endo-6 (-92\% ee and > 98:2 endo:exo ratio, Scheme 4). ${ }^{12}$

The first example of the enantioselective 1,3-DC of amino acid derived azomethine ylides and maleimides by using a very stable and recyclable chiral $(R)$ - or $(S)$-Binap 9- $\mathrm{AgClO}_{4}$ complexes (5 mol\%), has been described. ${ }^{13}$ The reactions were performed at room temperature, in toluene, in good yields, with high endo-diastereoand enantioselectivity, the catalytic chiral complex being recovered by simple filtration. In this reaction a substoichiometric amount of triethylamine (5 mol\%) was required. Although the $\left(R_{\mathrm{a}}\right)$ - and $\left(S_{\mathrm{a}}\right)$-Binap 9-AgClO complexes (formed by mixing equimolar amounts of both chiral ligands and $\mathrm{AgClO}_{4}$ ) were very insoluble in toluene, they efficiently catalysed the 1,3-DCR of azomethine ylides derived from $5\left(\mathrm{R}^{1}=\mathrm{H}, \mathrm{R}^{2}=\mathrm{Me}\right)$ and $N$-methylmaleimide (NMM), at room temperature in $17 \mathrm{~h}$, to yield endoadducts 6 (from 95:5 to > 98:2 endo:exo ratio, and from 80 to $>99 \%$ ee $)$. The same catalyst $\left(S_{\mathrm{a}}\right)$-Binap $\mathbf{9}-\mathrm{AgClO}_{4}$ (89-92\% recovery yield) was able to catalyse efficiently five batches of new reactions without significant loss of enantioselectivity. In addition, dipoles derived from alanine $\left(\mathrm{R}^{2}=\mathrm{Me}\right)$, phenylalanine $\left(\mathrm{R}^{2}=\mathrm{Bn}\right)$, or leucine $\left(\mathrm{R}^{2}={ }^{i} \mathrm{Bu}\right)$ methyl esters, were also essayed obtaining the endo-pyrrolidines 6 (> 98:2 endo:exo ratio in all cases) in good yields (56-81\%) but lower enantioselections (from 72 to $98 \%$ ee) (Scheme 3). Moreover, these complexes $(R)-\left(S_{\mathrm{a}}\right)-9-\mathrm{AgClO}_{4}$ were very stable to light exposure, and their isolation, storage and manipulation did not require any especial care or glove box conditions. Once more, this type of cycloaddition demonstrated its sensitivity to the electronic nature and the bulkiness of the substituents attached to the $\alpha$-position of the imino ester $\mathbf{5} .^{13}$

Chiral phosphoramidites $\mathbf{1 0}$ and $\mathbf{1 1}$ were tested as chiral ligands for silver(I) cation in the reaction shown in Scheme 3. ${ }^{14}$ The formation of these first monodentate chiral ligand $/ \mathrm{AgClO}_{4}$ complexes afforded not so stable metallic aggregates such as it was reported in the case of $(R)$ - or $(S)$-Binap 9- $\mathrm{AgClO}_{4}$ complexes. ${ }^{13}$ However, the 1,3$\mathrm{DC}$ of iminoesters 5 performed with $\left(S_{\mathrm{a}}, R, R\right)-\mathbf{1 1}-\mathrm{AgClO}_{4}$ achieved one of the wider scope transformations reported to date. In all cases, the $\left(S_{\mathrm{a}}, R, R\right)-\mathbf{1 1}-\mathrm{AgClO}_{4}$ complex afforded catalytically products with the stereochemistry corresponding to cycloadducts endo-6 (Scheme 3), in more than 98:2 ratio (according to ${ }^{1} \mathrm{H}$ NMR spectroscopy). ${ }^{14}$ Methyl arylideneiminoglycinates $5\left(\mathrm{R}^{1}=\mathrm{H}, \mathrm{R}^{2}=\mathrm{Me}\right)$ reacted in toluene at $-20^{\circ} \mathrm{C}$, and in the presence of $5 \mathrm{~mol} \%$ of $\mathrm{Et}_{3} \mathrm{~N}$ as base, with the following dipolarophiles: tertbutyl acrylate (67-83\% yield and up to $99 \%$ ee), NMM (at $\mathrm{rt}, 80 \%$ yield and $>99 \% e e$ ), dialkyl fumarates (79$81 \%$ yield and $82 \% e e$ ), chalcone and cyclopenten-2-one
(72-82\% yield and $82 \%$ ee and $94 \%$ ee, respectively). 1,3-Dipoles derived from $\alpha$-substituted $\alpha$-amino acids such as alanine, leucine and phenylalanine afforded very high yields and good to excellent enantioselections, especially when tert-butyl acrylate (70-78\% yield and up to $98 \%$ ee) or NMM (71-80\% yield and up to $90 \%$ ee ) were employed as dipolarophiles in toluene at $-20^{\circ} \mathrm{C}$ for $48 \mathrm{~h}$.

In both $\left(S_{\mathrm{a}}\right)$-Binap 9- $\mathrm{AgClO}_{4}{ }^{13}$ and $\left(S_{\mathrm{a}}, R, R\right)$ 11- $\mathrm{AgClO}_{4}{ }^{14}$ catalysed processes it was demonstrated that, as expected, the TS responsible for the enantiodiscrimination was quite asynchronous, detecting appreciable clashes between the dipole-containing coordination sphere and the dipolarophile.

The more sophisticated phosphoramidite $\mathbf{1 2}$ was put together with AgOAc and the resulting catalytic mixture screened in the $1,3-\mathrm{DC}$ reaction of methyl arylideneiminoglycinates $\mathbf{5}$ with dimethyl maleate as dipolarophile in the presence of $\mathrm{Et}_{3} \mathrm{~N}(10 \mathrm{~mol} \%)$ in $\mathrm{Et}_{2} \mathrm{O}$ as solvent at $-25^{\circ} \mathrm{C}$ for $15 \mathrm{~h}$. This complex induced the stereochemistry corresponding to the adduct ent-endo-6 (Scheme 3), with very high endo-diastereoselectivity (>99:1), excellent yield (93-98\%) and very high enantioselectivities (up to $99 \%$ ee). The main drawback of this process is that neither NPM, nor tert-butyl acrylate afforded high enantioselections. However, when dimethyl fumarate was used as dipolarophile, the ent-endo-cycloadduct $\mathbf{6}$ was isolated in quantitative yield and $84 \% e e .^{15}$

Recently, the 1,3-DC of iminoesters $5\left(\mathrm{R}^{1}=\mathrm{H}\right.$, $\left.\mathrm{R}^{2}=\mathrm{Me}\right)$ with maleimides has been performed using the chiral biaryl ligand $(S)$-13-AgOAc (3 mol\%) as catalyst. ${ }^{16}$ The reaction took place in 3-6 $\mathrm{h}$ at room temperature, in DCM, and in the absence of any base. Chemical yields and enantioselectivities were very high (81-99\% and up to $99 \% e e$ ), but the most interesting feature of this catalytic asymmetric process was the ability to run 1,3-DC with $\alpha$-substituted iminoesters 5 ( $\mathrm{R}^{1}=\mathrm{Me}$, 3-indolylmethyl, benzyl, phenyl, $\mathrm{R}^{2}=\mathrm{Me}$ ) and maleimides. In this case, yields and enantioselectivities were excellent (83-99\%, for 14 examples with 94-99\% ee). Dimethyl fumarate and tert-butyl acrylate also gave good results as dipolarophiles. The absolute configuration of cycloadducts, generated by this catalytic mixture, corresponded to the ent-endo-6 structure (Scheme 3). Moreover, the commercially available glycine ethyl ester benzophenone Schiff base $\mathbf{1 6}\left(\mathrm{R}^{1}=\mathrm{Ph}\right)$ was an equally acceptable dipolar partner for the generation of ent-endo-17 adduct in excellent yield with a $95 \%$ ee (Scheme 5). ${ }^{16}$

The copper(I)-catalysed enantioselective 1,3-DCR, was much more effective than the analogous reaction performed with chiral copper(II)-complexes. ${ }^{5}$ In most of the cases, the exo-diastereseselectivity is almost complete 


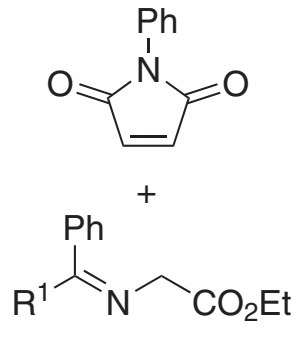

16

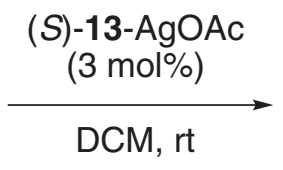

$(97 \%)$

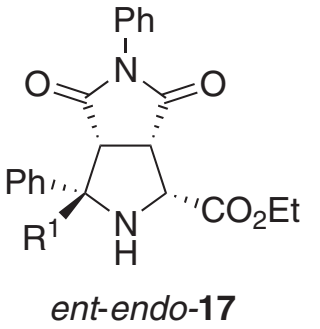

(>98:2 dr, 95\% ee)

Scheme 5 .

obtaining in several examples mixtures of endo- and exocycloadducts. A similar number of publications of chiral silver(I) and copper(I)-complexes have been reported. In the Figure 4 chiral ligands together with their optimised copper(I) salt are shown.

The model reaction described in Scheme 3 is analogous to the reaction shown in the Scheme 6, which differs only in the catalytic complex employed and in the diastereoselectivity exhibited. In spite of their similarity, it can be emphasised that in a copper(I)-catalysed 1,3-DC of azomethine ylides and dipolarophiles the major isolated product can be the exocycloadducts 7 or their ent-exo-7 derivatives, although some examples furnished the corresponding endo-stereoisomers 6 in very high percentages. This fact differs from the tendency observed in the silver(I)-catalysed processes, which exclusively yield the endo-cycloaddition products 6 . Unlike to silver promoted 1,3-DC, in the copper(I) mediated reactions, the presence of a base is always necessary due to poor basicity of the copper(I) salts employed during the formation of the chiral active complex.

The complex formed by chiral ligand $\left(S, S_{\mathrm{p}}\right)-\mathbf{1 8 a}-\mathrm{CuClO}_{4}$ (5 mol\%) (Figure 4) efficiently catalysed the 1,3-DC of methyl arylideneiminoglycinates $5\left(\mathrm{R}^{1}=\mathrm{H}, \mathrm{R}^{2}=\mathrm{Me}\right)$ with acrylates, in THF as solvent, during $20 \mathrm{~h}$ at $-20^{\circ} \mathrm{C}$. Diazabicyclo[5.4.0] undec-7-ene (DBU) or $\mathrm{Et}_{3} \mathrm{~N}$ were the most suitable bases affording exo-cycloadducts 7 in high chemical yields (65-87\%), very high exo:endo ratios (up to $98: 2$ ) and very good enantioselectivities (81-98\% ee). ${ }^{17}$

A similar chiral copper(I) complex formed with ligand $\left(S, S_{\mathrm{p}}\right) \mathbf{- 1 8 b}(10 \mathrm{~mol} \%)$ was employed in the 1,3 $\mathrm{DC}$ of azomethine ylides, generated from $5\left(\mathrm{R}^{1}=\mathrm{H}\right.$, $\mathrm{R}^{2}=\mathrm{Me}$ ), with nitroalkenes as dipolarophiles. Again exo-cycloadducts 7 were obtained as major diasteroisomers (86:14 to > 99:1 exo:endo ratio, and 70-98\% chemical yield) when the reaction was performed at $0{ }^{\circ} \mathrm{C}$ employing $\mathrm{KO}^{t} \mathrm{Bu}(10 \mathrm{~mol} \%)$ as base. The authors found a dramatic switch in the diasereoselectivity while still keeping high enantioselectivity. The endo-adducts 6 were obtained as major products (19:81 to 6:94 exo:endo ratio,
84-99\% ee, and 79-98\% yield) when employing $\left(S, S_{\mathrm{p}}\right)-\mathbf{- 1 8 b}$ and $\left(S, S_{\mathrm{p}}\right)-\mathbf{1 8 c}(10 \mathrm{~mol} \%)$ as ligands and using identical reaction conditions. This fine-tuning of the stereochemistry represents an exceptional example, which was attributed, according to computational studies, to different complexation models due to different electronic properties of the ligands $\mathbf{1 8} .^{18}$

The complexes formed by Fesulphos $\left(R_{\mathrm{p}}\right)-\mathbf{1 9 a}-\mathrm{Cu}^{\mathrm{I}}$ salts or its derivative $\left(R_{\mathrm{p}}\right) \mathbf{- 1 9 b}-\mathrm{Cu}^{\mathrm{I}}$ salts (Figure 4) allowed to react a variety of 1,3-dipole precursors with a wide number of dipolarophiles. The complex $\left(R_{\mathrm{p}}\right)-\mathbf{1 9 a}-\left[\mathrm{Cu}(\mathrm{MeCN})_{4}\right]$ $\mathrm{ClO}_{4}(3 \mathrm{~mol} \%)$ unexpectedly catalysed the $1,3-\mathrm{DC}$ reactions of iminoesters 5 and maleimides at $-10^{\circ} \mathrm{C}$ and using $\mathrm{Et}_{3} \mathrm{~N}$ (18 $\mathrm{mol} \%$ ) in DCM for $1 \mathrm{~h}$, to yield endo-cycloadducts 6 (81-97\% yield and $>99 \%$ ee $)$. However, important endo:exo-mixtures were achieved when the reaction was carried out with dimethyl maleate (67:33 endo:exo ratio), dimethyl fumarate (90:10 endo:exo ratio), and methyl acrylate (75:25 endo:exo ratio), obtaining simultaneously good chemical yields and high enantioselectivities (up to $95 \%$ and up to $>99 \%$ ee, respectively). $\beta$-Nitrostyrene gave almost a total exo-diastereoselectivity giving rise the compound exo-7 (Scheme 6) in 61\% yield, 95:5 endo:exo ratio, and $95 \%$ ee.$^{19,20}$ Following these reaction conditions, iminoesters derived from alanine $5\left(\mathrm{R}^{1}=\mathrm{R}^{2}=\mathrm{Me}\right)$ also reacted with different dipolarophiles in moderate to good yields (50-78\%), high endo-selectivity (> 98:2 endo:exo ratio) and good enantioselection (80-92\% ee).

The reaction described in Scheme 5 was successfully implemented by this chiral catalytic system not only when using the starting material $16\left(\mathrm{R}^{1}=\mathrm{Ph}\right)$ and NPM as dipolarophile, but also working with the acetophenone imine of the methyl glycinate in $1 \mathrm{~h}$. In both situations, yields (80-92\%), endo-diastereoselection (>98:2, endo-exo ratio) and enantioselection $(93->93 \%$ ee $)$ of the endocycloadduct $\mathbf{1 7}$ are high, demonstrating the utility of this reaction (Schem e 5). ${ }^{19,20}$

The 1,3-DC between iminoesters 5 and 1,2-bis(phenylsulphonyl)ethylene $\mathbf{2 6}$ was optimised 


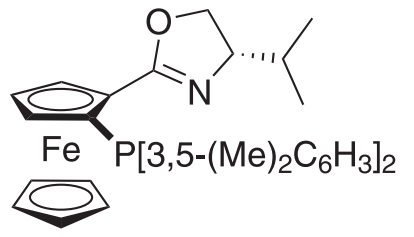

$\left(S, S_{p}\right)-\mathbf{1 8 a} / \mathrm{CuClO}_{4}$

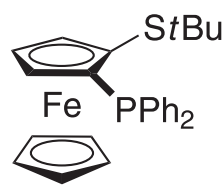

$/ \mathrm{CuClO}_{4}$

$\left(R_{\mathrm{p}}\right)-19 \mathrm{a} \quad / \mathrm{Cu}(\mathrm{MeCN})_{4} \mathrm{ClO}_{4}$ Fesulphos / $\mathrm{Cu}(\mathrm{MeCN})_{4} \mathrm{PF}_{6}$

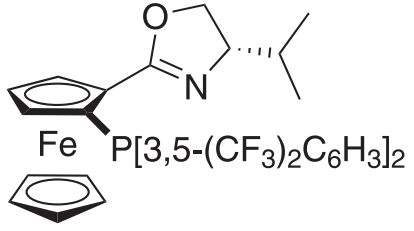

$\left(S, S_{p}\right)-\mathbf{1 8 b} / \mathrm{CuClO}_{4}$

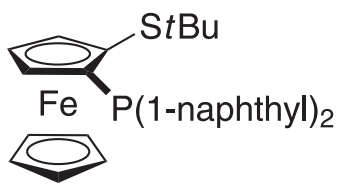

$\left(R_{\mathrm{p}}\right)-19 \mathrm{~b}$
/ $\mathrm{CuClO}_{4}$

/ $\mathrm{Cu}(\mathrm{MeCN})_{4} \mathrm{ClO}_{4}$

$/ \mathrm{Cu}(\mathrm{MeCN})_{4} \mathrm{PF}_{6}$

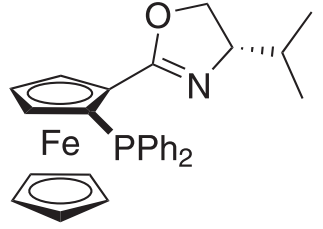

$\left(S, S_{p}\right)-18 c / \mathrm{CuClO}_{4}$

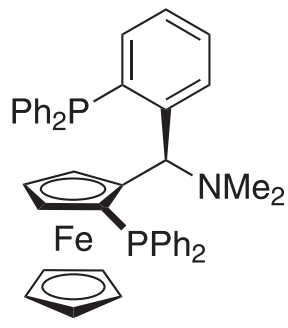

$\left(R, S_{\mathrm{p}}\right)-20 / \mathrm{CuClO}_{4}$ Taniaphos<smiles>COCc1ccccc1P(=O)(O)c1ccccc1</smiles>

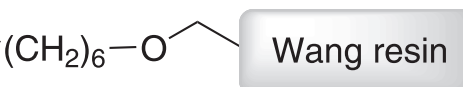

$\left(R_{\mathrm{p}}\right)-\mathbf{2 1} \quad / \mathrm{Cu}(\mathrm{MeCN})_{4} \mathrm{ClO}_{4}$

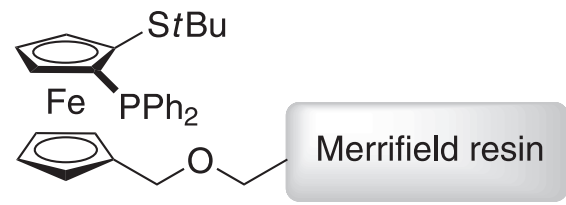

$\left(R_{\mathrm{p}}\right)-22 \quad / \mathrm{Cu}(\mathrm{MeCN})_{4} \mathrm{ClO}_{4}$<smiles>S=[P+](N[PH](=S)NC(c1ccccc1)c1ccccc1)c1ccccc1</smiles>

$(S, S)-23 / \mathrm{Cu}(\mathrm{MeCN})_{4} \mathrm{ClO}_{4}$<smiles>CC(c1ccccc1)n1nnc(-c2ccccc2)c1-c1ccccc1</smiles>

$\left(S, R_{\mathrm{p}}\right)-24$ ClickFerrophos<smiles>Nc1c(Br)c(C(F)(F)F)cc(C(F)(F)F)c1-c1c(C(F)(F)F)cc(C(F)(F)F)c(Br)c1NPc1ccccc1</smiles>

(S)-13 / $\mathrm{CuBF}_{4}$

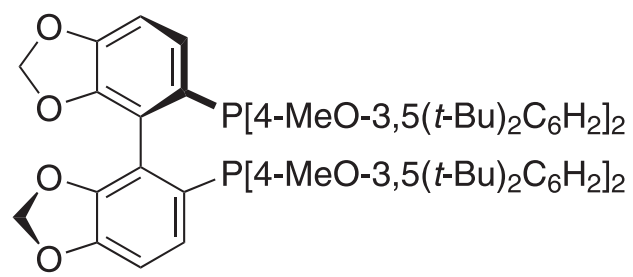

\section{$\left(R_{\mathrm{a}}\right)-25 / \mathrm{Cu}(\mathrm{MeCN})_{4} \mathrm{PF}_{6}$}

Figure 4. Chiral ligands/copper(I) salts used to generate chiral Lewis acids employed in 1,3-DC of azomethine ylides 5 and dipolarophiles.

using the $\left(R_{\mathrm{p}}\right)-\mathbf{1 9 a}-\left[\mathrm{Cu}(\mathrm{MeCN})_{4}\right] \mathrm{PF}_{6}$ complex (Figure 4) in THF at room temperature, in the presence of $\mathrm{Et}_{3} \mathrm{~N}(20 \mathrm{~mol} \%)$ as base. The exclusively generated exo-cycloadducts 7 were obtained in good yields and very good enantioselections (Scheme 7 , reaction a). These proline derivatives $\mathbf{7}$ are very attractive substrates, especially the exo-adduct $7\left[\mathrm{Ar}=4-\left(\mathrm{Boc}_{2} \mathrm{~N}\right) \mathrm{C}_{6} \mathrm{H}_{4}\right]$, which was the direct precursor of pyrrolidine dihydrochloride 27, a promising trypanosomal nucleoside hydrolase inhibitor, isolated after six conventional synthetic steps (Scheme 7, reaction b). ${ }^{21}$ According to the reaction conditions described in reaction a of Scheme 7, the exo-cycloadduct 


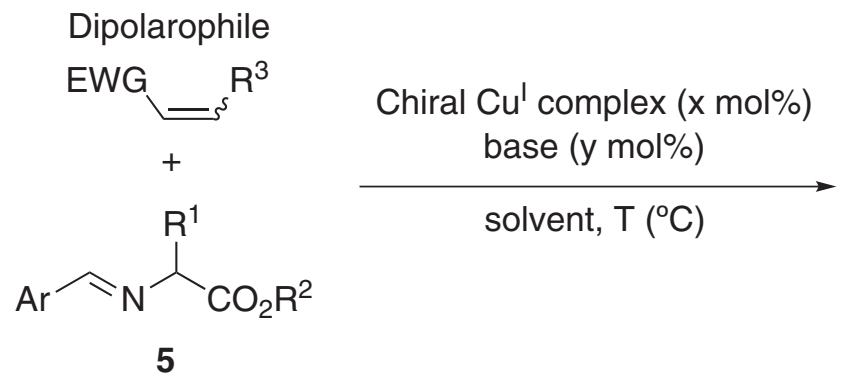
In several examples
the endo-cycloadducts
are the major products

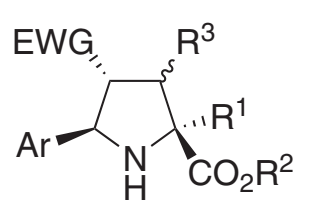

exo-cycloadduct 7

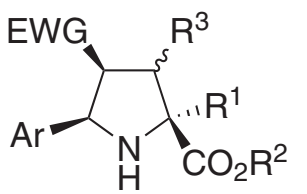

endo-cycloadduct 6

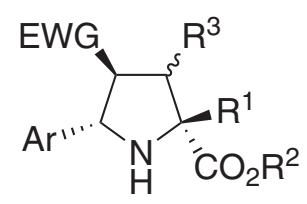

ent-7-exo-cycloadduct

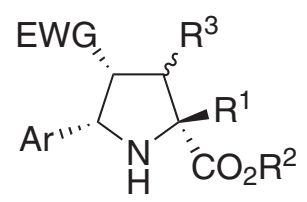

ent-6-endo-cycloadduct

Scheme 6. Model reaction for chiral copper(I) complex catalysed 1,3-DCs.

7 was generated with a $85 \%$ ee, but a higher enantiomeric purity was needed for the synthesis of antihelminthic agent 27. For this purpose, modified chiral ligands were evaluated, finding that the complex formed by ligand $\left(R_{\mathrm{p}}\right)-\mathbf{1 9 b}$ and $\left[\mathrm{Cu}(\mathrm{MeCN})_{4}\right] \mathrm{PF}_{6}$ salt $(3 \mathrm{~mol} \%$ each) catalysed the cycloaddition in DCM (with a $20 \mathrm{~mol} \%$ of $\mathrm{Et}_{3} \mathrm{~N}$ ) at $-78^{\circ} \mathrm{C}$ for $48 \mathrm{~h}$ giving the corresponding exo-adduct 7 $\left[\mathrm{Ar}=4-\left(\mathrm{Boc}_{2} \mathrm{~N}\right)-\mathrm{C}_{6} \mathrm{H}_{4}\right]$ in $85 \%$ yield with a $94 \% e e .^{21}$

A large series of examples of 1,3-DC involving Schiff bases 5 were reported to be reactive with $\alpha, \beta$-unsaturated ketones using $\left(R_{\mathrm{p}}\right)-\mathbf{1 9 a}$ or $\left(R_{\mathrm{p}}\right)-\mathbf{1 9 b}-\left[\mathrm{Cu}(\mathrm{MeCN})_{4}\right] \mathrm{ClO}_{4}$ $(5 \mathrm{~mol} \%)$ as catalysts in the presence of $\mathrm{Et}_{3} \mathrm{~N}(18 \mathrm{~mol} \%)$ in
$\mathrm{DCM}$ at room temperature. The reaction with cyclic enones afforded endo-cycloadducts 6 (50-70\% yields and $85-95 \%$ $e e)$, but $(E)$-acyclic enones furnished exo-cycloadducts 7 (45-85\% yield and $81-96 \% e e$ ). This different behaviour was justified by stereoelectronic effects during the approach of the dipolarophile to the chiral formed metallodipole. ${ }^{22}$

Aryl vinyl sulfones 28, acting as a synthetic equivalent of ethylene, were suitable dipolarophiles in the 1,3-DC with methyl arylideneiminoglycinates $5\left(\mathrm{R}^{1}=\mathrm{H}, \mathrm{R}^{2}=\mathrm{Me}\right)$. The reaction, catalysed by $\left(S_{\mathrm{p}}\right)$-Taniaphos $\mathbf{2 0}-\left[\mathrm{Cu}(\mathrm{MeCN})_{4}\right] \mathrm{ClO}_{4}$ (10 mol\%) (Figure 4) and $\mathrm{Et}_{3} \mathrm{~N}$ (18 mol\%), occurred in toluene, at $0{ }^{\circ} \mathrm{C}$ for $4-24 \mathrm{~h}$, in good yields (71-91\%), with

reaction a)

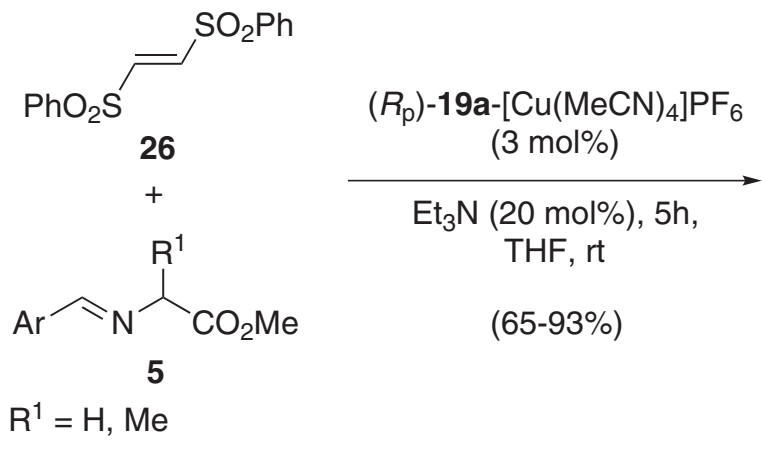<smiles>[2H][C@@]1(C(=O)OC)NC([Al])[C@@H](S(=O)(=O)Oc2ccccc2)[C@H]1S(=O)(=O)c1ccccc1</smiles>

exo-cycloadduct 7 (>98:2 exo:endo) $(85-99 \%$ ee $)$

reaction b)

$$
\begin{aligned}
& \mathrm{Ar}=4-\left(\mathrm{Boc}_{2} \mathrm{~N}\right) \mathrm{C}_{6} \mathrm{H}_{4} \\
& (94 \% \text { ee) }
\end{aligned}
$$<smiles>Nc1ccc([C@H]2N[C@H](CO)[C@@H](O)[C@H]2O)cc1</smiles>

(>99\% ee) 

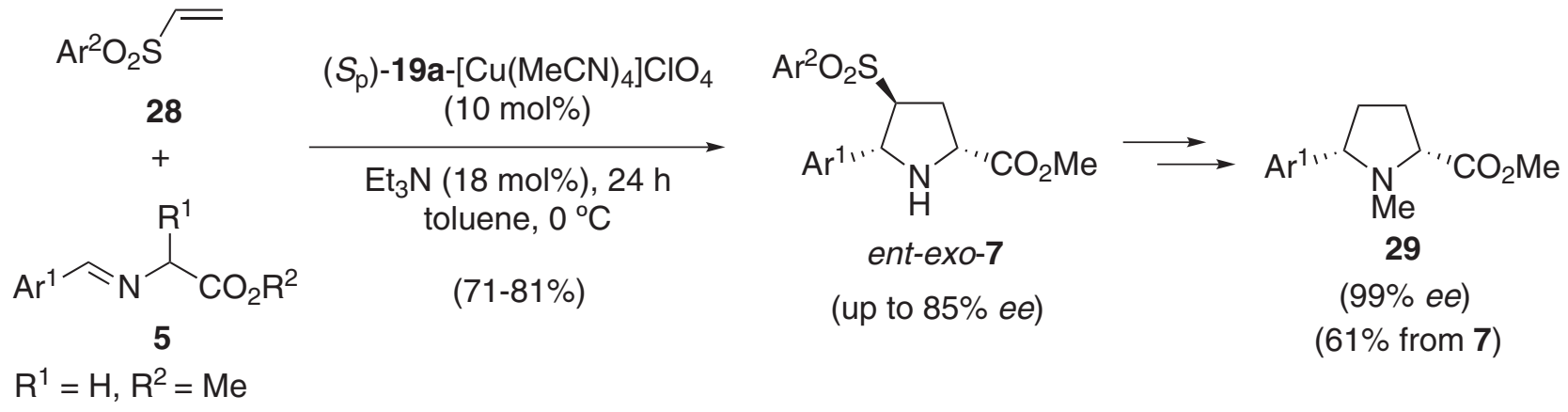

Scheme 8.

total exo-diastereocontrol and good enantioselection in the final ent-exo-7 cycloadducts. These compounds were finally transformed into the corresponding cis-2,5-disubstituted pyrrolidines 29 in good yields after a desulfonylation employing sodium amalgam (Scheme 8). ${ }^{23}$

Polymer-supported Fesulphos ligands $\left(R_{\mathrm{p}}\right)-\mathbf{2 1}$ and $\left(R_{\mathrm{p}}\right)$-22 (Figure 4) were prepared and further applied to the copper(I)-catalysed 1,3-DC of azomethine ylides and alkenes. Iminoesters $5\left(\mathrm{R}^{1}=\mathrm{H}, \mathrm{R}^{2}=\mathrm{Me}\right)$ reacted with maleimides using $\left(R_{\mathrm{p}}\right)-\mathbf{2 1}$ or $\left(R_{\mathrm{p}}\right)-\mathbf{2 2}-\left[\mathrm{Cu}(\mathrm{MeCN})_{4}\right] \mathrm{ClO}_{4}$ (3 mol\%) and $\mathrm{Et}_{3} \mathrm{~N}(18 \mathrm{~mol} \%)$ as catalysts in DCM at $-10{ }^{\circ} \mathrm{C}$ affording endo- 6 compounds in 55-98\% yield, more than 98:2 endo:exo ratio, and excellent enantioselectivities (98- > $99 \%$ ee).

The reaction depicted on Scheme 5 was also performed with the starting material $\mathbf{1 6}\left(\mathrm{R}^{1}=\mathrm{Ph}\right)$ under the last reaction conditions furnishing endo-17 adducts in $95 \%$ yield and $98 \%$ ee. The ligand $\left(R_{\mathrm{p}}\right)-\mathbf{2 1}$ was the most appropriate to run the catalytic 1,3-DC of $5\left(\mathrm{R}^{1}=\mathrm{H}, \mathrm{R}^{2}=\right.$ $\mathrm{Me}$ ) with dimethyl maleate giving the endo-product $\mathbf{6}$ in 92\% yield, 80:20 endo:exo ratio and 98\% ee. The ligand was finally recovered by filtration but a great depletion of the enantioselectivity in the second run was observed (from 99\% ee in the first run, to $80 \%$ ee in the second cycle). ${ }^{24}$

The chiral bisthiophosphoramide $(S, S)-23-\left[\mathrm{Cu}(\mathrm{MeCN})_{4}\right]$ $\mathrm{ClO}_{4}(5 \mathrm{~mol} \%$ ) (Figure 4) was tested in the reaction of iminoesters $5\left(\mathrm{R}^{1}=\mathrm{H}, \mathrm{R}^{2}=\mathrm{Me}\right)$ and maleimides, obtaining not so spectacular enantioselections. The endo-6 cycloadducts were obtained in good yields (76-89\%) and moderate enantioselectivities (26-79\% ee) ${ }^{25}$

The chemistry developed with Clickferrophos $\left(R_{\mathrm{p}}\right)$ 24-CuOAc (Figure 4) ${ }^{26}$ was very similar to that described for Ferrophos 19a or ligand 19b-copper(I) complexes. ${ }^{23}$ Substrates $5\left(\mathrm{R}^{1}=\mathrm{H}, \mathrm{R}^{2}=\mathrm{Me}\right)$ reacted with phenyl vinyl sulfone (80-91\%), acrylates (87-89\%), dimethyl maleate (66\%), dimethyl fumarate (71\%), and NPM (95\%), in diethyl ether at $-40^{\circ} \mathrm{C}$, for $24 \mathrm{~h}$, in the absence of an extra base. The ent-exo-cycloadducts 7 were obtained as the major diastereoisomers (70:30 to 99:1 exo:endo ratios) with very high enantioselectivities, 93-99\% ee for vynyl sulfone, 91-96\% ee for acrylates, $80 \%$ ee for methyl maleate, $91 \%$ $e e$ for dimethyl fumarate, and $91 \% e e$ for NPM. ${ }^{26}$

Ligand $\left(S_{\mathrm{a}}\right)$-13 (Figure 4), tested in the silver(I) catalysed 1,3-DC of azomethine ylides, ${ }^{16}$ was also used as the partner of $\mathrm{CuBF}_{4}$ as catalyst ( $\left.3 \mathrm{~mol} \%\right)$. The reaction occurred at $0{ }^{\circ} \mathrm{C}$ in DCM and using $\mathrm{Et}_{3} \mathrm{~N}(15 \mathrm{~mol} \%)$ as base. In general, the reactions performed using the two different metal salts are chemically identical, but the enantioselections achieved of the ent-endo- $\mathbf{6}$ adduct were higher in the case of copper(I)-catalysed process (always in the range from 99 to $>99 \% \mathrm{ee}$ ), independently of the used 1,3-dipole precursor (glycinates or alaninates $\mathbf{5}$, and iminoester 16) or the dipolarophile (maleates, fumarates or acrylates). ${ }^{27}$

The 1,3-DC of (Z)-sulfonyl acrylates $\mathbf{3 0}$ and azomethine ylides was an interesting transformation in which the regioselectivity of the cycloaddition was mainly controled by the sulfonyl group providing pyrrolidine 2,3-dicarboxylic esters with very high both exo-diastereoselectivity (up to > 80:20) and enantioselectivity (88-99\% ee) of the ent-exo-7 cycloadduct (Scheme 9). ${ }^{28}$ The reaction took place with the chiral Segphos derivative $\left(R_{\mathrm{a}}\right)-25-\left[\mathrm{Cu}(\mathrm{MeCN})_{4}\right] \mathrm{PF}_{6}(5 \mathrm{~mol} \%)$ (Figure 4), $\mathrm{Et}_{3} \mathrm{~N}(18 \mathrm{~mol} \%)$ as base in DCM at room temperature. The straightforward reductive elimination with $\mathrm{Na}(\mathrm{Hg})$ alloy led to the corresponding pyrrolidine 2,3-dicarboxylic esters $\mathbf{3 1}$ in good yields and excellent diastereoselections (Scheme 9). These products are difficult to be obtained employing other different methodologies.

Other metal-catalysed 1,3-DC were tested obtaining very interesting results and applications. Zinc(II), calcium(II), gold(I), or nickel(II) chiral complexes (Figure 5) afforded exclusively endo-cycloadducts in very good yield.

The chiral ligand 32-Zn(OTf) ${ }_{2}$ (Figure 5) complex was employed as catalyst for the 1,3-DC of arylideneglycinates $5\left(\mathrm{R}^{1}=\mathrm{H}, \mathrm{R}^{2}=\mathrm{Me}\right)$ according to the Scheme $10 .{ }^{29}$ The reaction was carried out with $\mathrm{Et}_{3} \mathrm{~N}(10 \mathrm{~mol} \%)$ in DCM at $-20{ }^{\circ} \mathrm{C}$. The chemical yields were good and the 


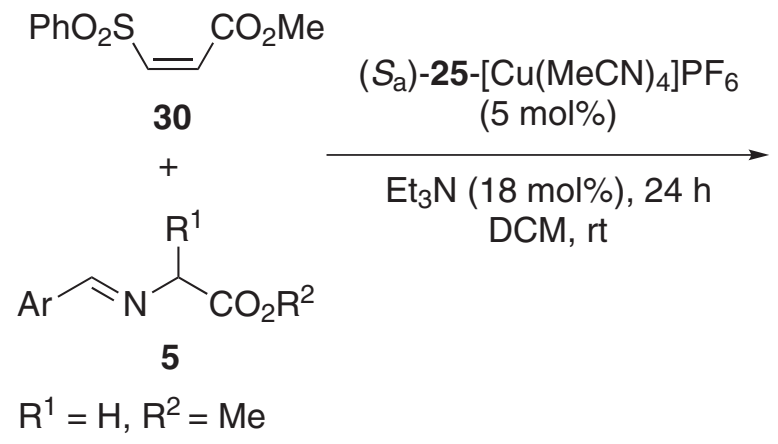

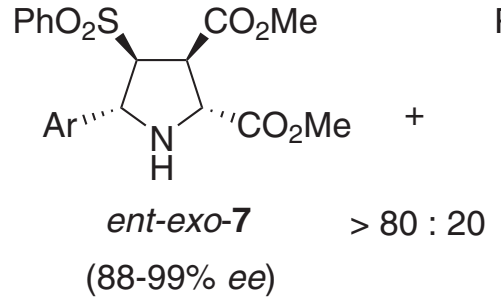

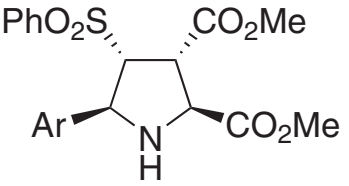

exo-7
$(62-80 \%)$

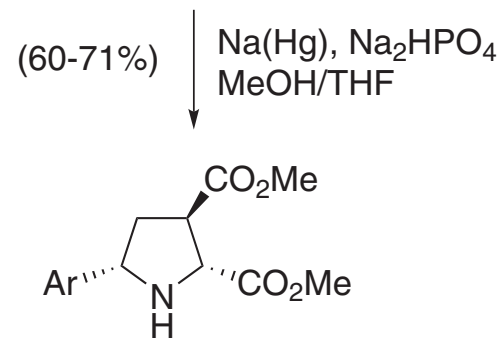

31

$(99 \%$ ee $)$

Scheme 9.

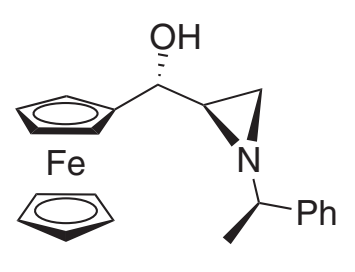

$32 / \mathrm{Zn}(\mathrm{OTf})_{2}$<smiles>CCOc1ccc2c(c1-c1c(P)ccc3c1OCO3)OCO2</smiles>

$\left(S_{\mathrm{a}}\right)$-Cy-Segphos $35 \quad /(\mathrm{AuOBz})_{2}$<smiles>[R]C1COC(CC2=NC([R])CO2)=N1</smiles>

33a, $\mathrm{R}=\mathrm{Ph} \quad / \mathrm{Ca}(\mathrm{OiPr})_{2}$ 33b, $\mathrm{R}=i \mathrm{Pr} / \mathrm{Ca}(\mathrm{O} i \mathrm{Pr})_{2}$<smiles>c1ccc2c(c1)CC1OC(CC3=N[C@H]4c5ccccc5CC4O3)=NC21</smiles>

$34 / \mathrm{Ca}(\mathrm{O} / \mathrm{Pr})_{2}$<smiles>C(=N/c1ccc2ccccc2c1-c1c(/N=C/c2ccccn2)ccc2ccccc12)\c1ccccn1</smiles>

\section{$\left(R_{\mathrm{a}}\right)-36 \quad / \mathrm{Ni}\left(\mathrm{ClO}_{4}\right)_{2} \cdot 6 \mathrm{H}_{2} \mathrm{O}$}

Figure 5. Chiral ligands/zinc(II), calcium(II), gold(I), or nickel(II) salts used to generate chiral Lewis acids employed in 1,3-DC of azomethine ylides and alkenes.

enantioselectivity depended on the employed dipolarophile. Thus, with dimethyl maleate compound ent-endo-6 was achieved in $86-95 \% e e$, and with dimethyl fumarate the same compound was obtained in $68 \%$ ee, whilst tert-butyl acrylate and NMM afforded endo-cycloadducts with lower enantioselections (70-88\% ee).

A comprehensive study was done with chiral calcium(II) complexes derived from the ligands 33a and 34. As it was described in the precedent example, the endo-selectivity was in this case, almost complete in the more than fifty published examples. ${ }^{30}$ It is worthy to highlight the highest affinity of the chiral complex 33a-Ca(OiPr) ${ }_{2}(10 \mathrm{~mol} \%)$ for the 1,3-DC of tert-butyl dibenzylideneiminoglycinate and crotonates 38 . The endo-cycloadduct 39 was formed in THF at $-30{ }^{\circ} \mathrm{C}$ in the absence of and added base (Scheme 11, reaction a). On the other hand, chiral ligand $\mathbf{3 4}$ (Figure 5) (11 $^{31}$ was the appropriate one to perform the reaction of more sterically hindered 1,3-dipoles with crotonates, even with 


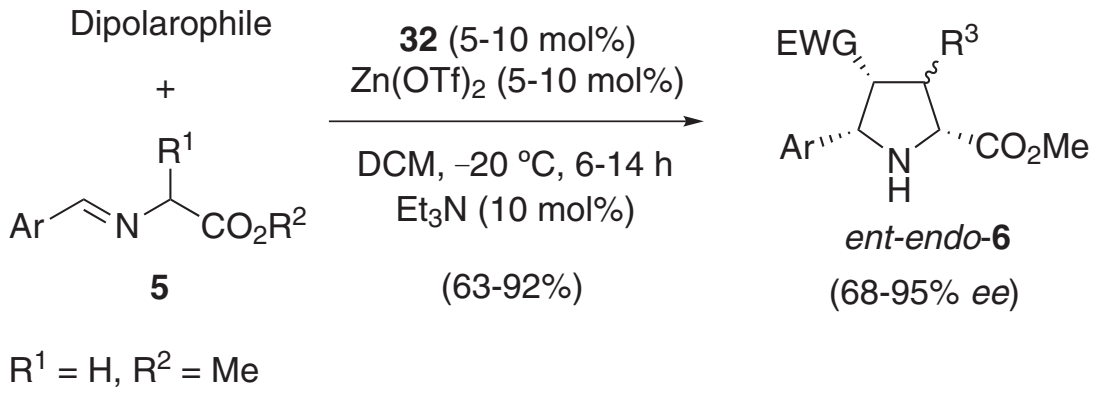

Scheme 10.

several acrylates. The chemical yields of the corresponding endo-adducts $\mathbf{4 0}$ were very high, and the level of the enantioselection was excellent, considering the large number of examples tested and described (Scheme 11, reaction b). A set of computational calculations confirmed once more the stepwise mechanism of these chiral Lewis acid-promoted 1,3-DC. From the economical and environmental points of view, the use of cheap and naturally abundant calcium metal is quite interesting. ${ }^{30}$

Activated azlactones 41, reacted with maleic anhydride, NPM, and acrylates to yield $\Delta^{1}$-pyrrolines $\mathbf{4 2}$ in good yields (68-89\%) and high enantioselections (76-99\% ee) (Scheme 12). ${ }^{32}$ The reaction occurred with the complex $(2 \mathrm{~mol} \%)$ formed by 2 equiv. of Segphos derived ligand $\mathbf{3 5}$ and 2 equiv. of $(\mathrm{AuOBz})_{2}$ at room temperature and employing a mixture of THF:fluorobenzene (for azlactones $\mathbf{4 1}, \mathrm{R}^{1}=$ $\mathrm{H})$ or fluorobenzene alone (for $\alpha$-substituted azlactones). Once the reaction was judged complete, a diazomethane surrogate or amines promoted the esterification or the formation of the amide, respectively, by the direct attack to the intermediate $\mathbf{4 3}$, which underwent a ring opening followed by a $\beta$-elimination regenerating the chiral gold complex (Scheme 12).

Chiral bis-imine $\left(R_{\mathrm{a}}\right)-36-\mathrm{Ni}\left(\mathrm{ClO}_{4}\right)_{2} \cdot 6 \mathrm{H}_{2} \mathrm{O}$ complex (5 mol\%) (Figure 5) was a useful catalyst for the reaction of iminoesters $5\left(\mathrm{R}^{1}=\mathrm{H}, \mathrm{R}^{2}=\mathrm{Me}\right)$ with maleimides, ${ }^{33}$

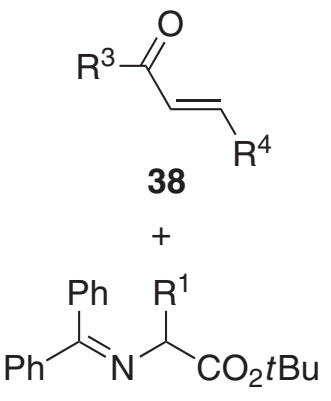

37<smiles>[R]C=CC([R3])=O</smiles><smiles>[R]OC([R])/N=C/[Te]</smiles>

5
$33(10 \mathrm{~mol} \%)$ $\mathrm{Ca}(\mathrm{O} / \mathrm{Pr})_{2}(10 \mathrm{~mol} \%)$

THF, $-30^{\circ} \mathrm{C}$, $4 \AA \mathrm{MS}$

(77\%-quant.)

reaction a)

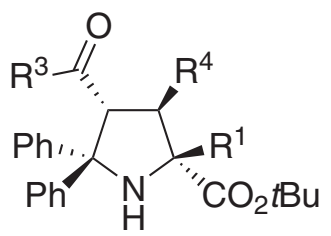

endo-39

(88->99\% ee)

reaction b)<smiles>[R]OC(=O)C1C([R7])C([R7])NC1(c1ccccc1)c1ccccc1</smiles>

(up to $98 \%$ ee)

$\mathrm{R}^{1}=\mathrm{H}, \mathrm{Me}$, Et, $n \mathrm{Bu}, \mathrm{Bn}, \mathrm{CH}_{2} \mathrm{O} t \mathrm{Bu}$

$\mathrm{R}^{2}=\mathrm{Me}, t \mathrm{Bu}$ 


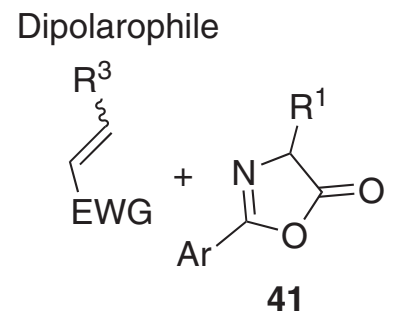

$\mathrm{R}^{1}=\mathrm{H}, \mathrm{Me}$, allyl, $\mathrm{Ph}, \mathrm{Bn}$

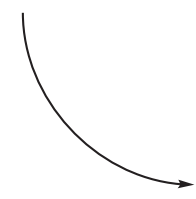

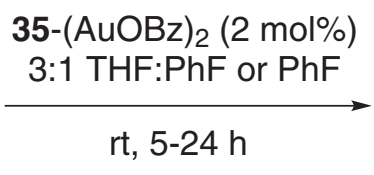

then $\mathrm{TMSCHN}_{2}$ or amine

$(68-89 \%)$

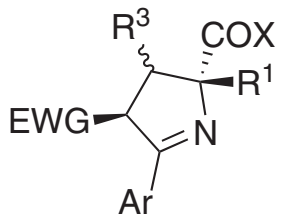

42

$(76-99 \%$ ee)

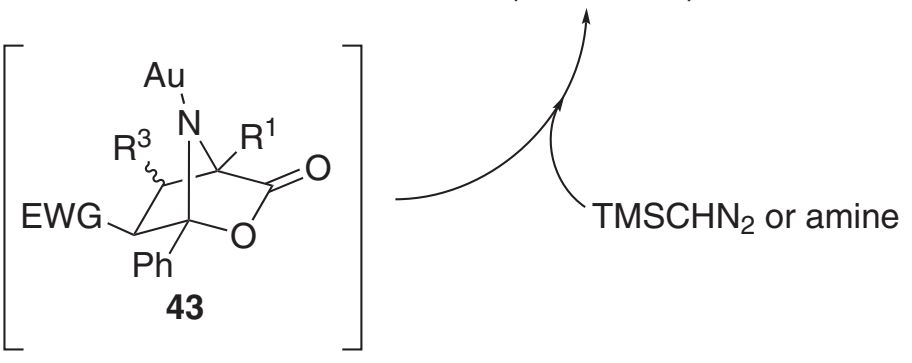

Scheme 12.

following the patterns depicted in Schemes 3 or 5 . In the presence of diisopropylethylamine (DIPEA) as base (10 $\mathrm{mol} \%$ ), and $4 \AA \mathrm{MS}$, in DCM at $15^{\circ} \mathrm{C}$ the endo-product 6 was diastereoselectively obtained in high yields (73-92\%) and very good enantioselections (82-95\% ee).

Asymmetric organocatalysis ${ }^{34}$ is a rapidly growing area and has recently applied to the 1,3-DCR but involving special azomethine ylides and $\alpha, \beta$-unsaturated carbonyl compounds. In Figure 6 the organocatalysts employed to date are described.

The 1,3-DC between azomethine ylides and alkenes was reported using $\mathrm{AgF}$ ( $5 \mathrm{~mol} \%$ ) and hydrocinchonine 44 (Figure 6) as chiral base in DCM, at $-24^{\circ} \mathrm{C}$ for 4 days. Although it was not a pure organocatalysed reaction, a chiral base was employed in substoichiometric amounts by the first time. The reaction was only performed with methyl arylideneglycinates $5\left(\mathrm{R}^{1}=\mathrm{H}, \mathrm{R}^{2}=\mathrm{Me}\right)$ and alkyl acrylates yielding endo- $\mathbf{6}$ cycloadducts $\left(\mathrm{R}^{3}=\mathrm{H}\right)($ Scheme 3$)$ in good yields (67-> 95\%) and modest enantioselections (up to $73 \% e e$ ), but in some cases the final products arose up to $92 \%$ ee after recrystallisation. ${ }^{35}$

The last reference inspired the application of the asymmetric phase-transfer catalysis (PTC) concept to these cycloadditions. In this particular case the reaction of tert-butyl alaninate $\mathbf{5 3}$ and methyl acrylate was surveyed. ${ }^{36}$ The selected ammonium salt 45 (Figure 6) was introduced in $5 \mathrm{~mol} \%$ loading, employing $\mathrm{CsOH}_{2} \mathrm{H}_{2} \mathrm{O}(20 \mathrm{~mol} \%)$ as base, in diethyl ether as solvent, at room temperature for $42 \mathrm{~h}$. As it was observed before the endo-diastereoselection was almost complete, probably due to the effect of the cesium cation, which has enough volume to favour several electronic interactions with methyl acrylate. Yields for compound $\mathbf{5 4}$ or the bicycle $\mathbf{5 5}$ were not satisfactory because the enantioselectivity obtained was very poor (25\% ee) (Scheme 13).

At this point, two serious drawbacks were detected in these organocatalysed 1,3-DC of azomethine ylides and alkenes, namely the enantioselectivities and the substitutions at the different positions of both the 1,3-dipole precursor and the dipolarophile. Later, it was discovered that the (S)-prolinol derivative 46 (in $20 \mathrm{~mol} \%$ amount, Figure 6) efficiently catalysed the 1,3-DC of arylideneiminomalonates 56 with $\alpha, \beta$-unsaturated aldehydes $\mathbf{5 7}$. The transformation needed long reaction times to proceed $(3 \mathrm{~d})$ in the presence of 4 equiv. of water in $\mathrm{THF}$ at $4{ }^{\circ} \mathrm{C}$. Any base was needed in the process, presumably an spontaneous 1,2-prototropy shift taking place in the activated starting compound $\mathbf{5 6}$. This feature, together with the activation of the aldehyde as its chiral pyrrolidinium ion, supported the transition state TS-IV. The authors proposed that an efficient blockage of the $S i$ face in the chiral iminium intermediate by the two bulky phenyl groups led to a stereoselective endo-type approach (Scheme 14). ${ }^{37}$ One disadvantage of this protocol is that the obtained products $\mathbf{5 8}$ required a multistep sequence to furnish the corresponding prolines.

An identical work, employing the analogous dipoles and dipolarophiles, was reported later with the novelty of using a multi-component reaction. Thus, and aldehyde, diethyl 2-aminomalonate 59, and $\alpha, \beta$-unsaturated aldehydes were mixed in the same flask reproducing exactly the reaction conditions described in Scheme 14, but in this occasion the $O$-TMS protected chiral pyrrolidine 47 (20 mol\%, Figure 6) was employed as organocatalyst. ${ }^{38}$ Yields (51-70\%) and enantioselectivities (90-98\% ee) of the endo-products $\mathbf{5 7}$ 
<smiles>CCC1CN2CCC1CN2[C@H](O)c1ccnc2ccccc12</smiles>

Hydrocinchonine 44<smiles>C=CC1CN2CCC1C2[C@H](NC(=S)Nc1cc(C(F)(F)F)cc(C(F)(F)F)c1)c1ccnc2ccc(OC)cc12</smiles>

48<smiles>CN(C)C1CCCC[C@@H]1NC(=S)Nc1cc(C(F)(F)F)cc(C(F)(F)F)c1</smiles>

50<smiles>BrCO[C@H]1CN2C[C@H](OC[Bi])N(CC1OC[Bi])C2</smiles>

45<smiles>OC(c1ccccc1)(c1ccccc1)C1CCCN1</smiles>

46<smiles>COC(c1ccccc1)(c1ccccc1)C1CCCN1</smiles>

47<smiles>O=P1(O)Cc2ccc3ccccc3c2-c2c(c(COCc3cc4ccccc4c4c3CP(=O)(O)Cc3ccc5ccccc5c3-4)cc3ccccc23)C1</smiles>

49<smiles>CCC1CN2CCC1C[C@H]2[C@H](O)c1ccnc2ccc(OC)cc12</smiles>

Hydroquinine

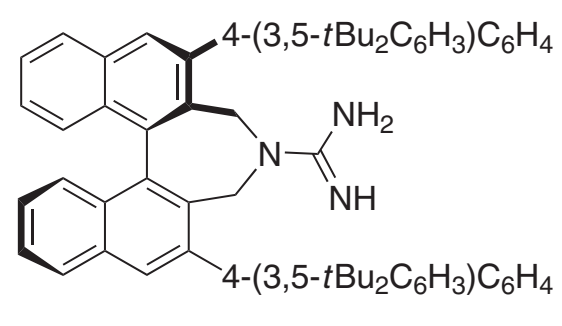

52

51

Figure 6. Organocatalysts employed for the enantioselective 1,3-DC of azomethine ylides and dipolarophiles.<smiles>C=CC(=O)OC(C)C(=O)OC(C)(C)C</smiles>

53<smiles>CCOC(=O)[C@]1(C)C[C@@H](C(C)C)N[C@H]1c1ccccc1O</smiles>

54 $(43 \%)$<smiles>CCCOC(=O)[C@]1(C)C[C@H]2C(=O)Oc3ccccc3[C@H]2N1</smiles>

55

$(13 \%)$
$(25 \%$ ee $)$

Scheme 13.

were very satisfactory, whilst the diastereoselectivity was moderate to good (from 4:1 to > 10:1 endo:exo ratio).

The first organocatalytic enantio- and diastereoselective 1,3-DC of azomethine ylides and nitroalkenes was optimised using the hybrid organocatalyst 48 (Figure 6), composed by a chiral quinuclidine core base and a chiral thiourea framework. ${ }^{39}$ This transformation was very limited because it was only applied to the reaction of the benzophenoneimine derivative $\mathbf{3 7}$ and different nitroalkenes 60, the catalyst 48 being used in $10 \mathrm{~mol} \%$ loading. The endo-adduct $\mathbf{6 1}$ was isolated with a high endo:exo ratio (88:12 to 95:5 $d r$ ) (Scheme 15). 
<smiles>[R7]C=CC=CC(C(=O)OCC)[C@@H](N=CBr)OCC</smiles>

56

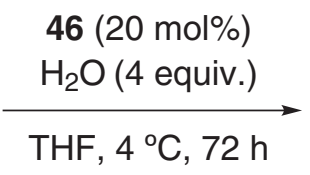

$(74-91 \%)$<smiles>[3H]C1[C@H](C=O)[C@@H]([Al])NC1(OCC)OCC</smiles>

endo-58

(85->99\% ee)

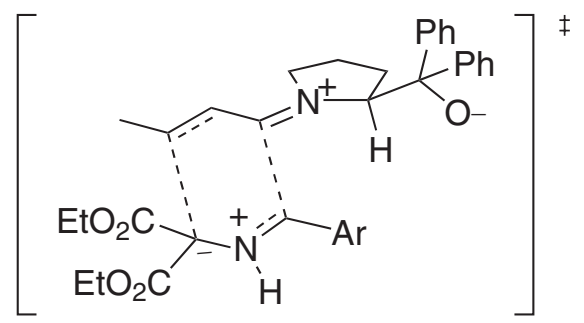

TS-IV

Scheme 14.

A series of $\alpha$-amino acids, such as proline, 3- and 4-hydroxyprolines, glutamic acid, tryptophan, among others, $(20-40 \mathrm{~mol} \%)$ were tested as catalysts in the 1,3-DC reaction of iminoesters 5 with maleimides, fumarates and maleic anhydride, in DCM at room temperature. ${ }^{40}$ Unfortunately, less than $12 \%$ ee was obtained of the endo-type cycloadducts 6 (see, Scheme 3 ).

In a more recent contribution, the already mentioned three-component reaction of diethyl 2-aminomalonate, an aldehyde, and dialkyl maleates (instead of $\alpha, \beta$-unsaturated aldehydes) was widely improved by employing the organocatalyst 49 (10 mol\%) (Figure 6). The reaction, performed in DCM at room temperature in the presence of $3 \AA$ MS, needed very long reaction times to achieve very high conversions. The endo- $\mathbf{6 3}$ cycloadducts were obtained as unique stereoisomers with yields ranging from 70 to $97 \%$, and very good to excellent enantioselectivities (76-99\% eе) (Scheme 16). ${ }^{41}$<smiles>[R]C=C[N+](=O)[O-]</smiles><smiles>CCOC(=O)CN=C(c1ccccc1)c1ccccc1</smiles>

37<smiles>[R]C1CC(C(=O)OCCCO)NC1(c1ccccc1)c1ccccc1</smiles>

$(50-62 \%$ ee)

Scheme 15.

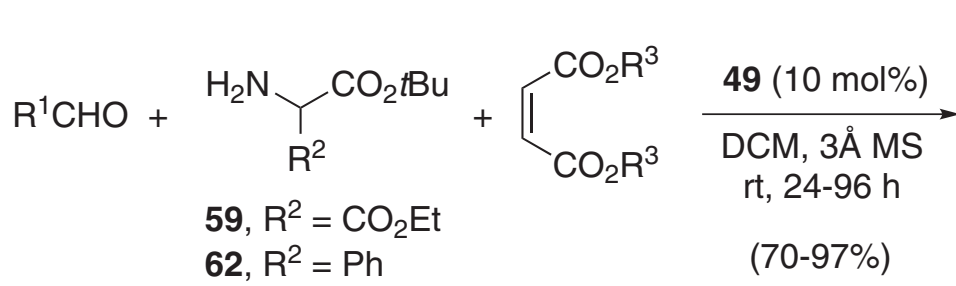

(70-97\%)

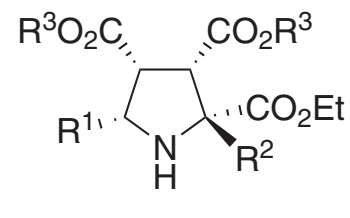

endo-63

(76-99\% ee) 
Thiourea-catalysed enantioselective 1,3-DC of ethyl 2-(arylideneimino)malonates $\mathbf{5 6}$ and nitroalkanes $\mathbf{6 0}$ was published postulating a two-step mechanism consisting on a first Michael-type addition, followed by an aza-Henry reaction. ${ }^{42}$ The catalyst $\mathbf{5 0}(10 \mathrm{~mol} \%)$, the 1,3-dipole precursor 56 and several nitroalkenes $\mathbf{6 0}$ were dissolved in toluene and allowed to react at $0{ }^{\circ} \mathrm{C}$ for $9 \mathrm{~h}$, then 2,2,2-trifluoroethanol (30 equiv.) was added, and the reaction continued at $0{ }^{\circ} \mathrm{C}$ for another additional $36 \mathrm{~h}$. This last additive, having a more acid proton than ethanol, was used to promote the aza-Henry reaction of the initially formed Michael-type adduct $\mathbf{6 4}$ to yield diastereoselectively (>91:9 dr), compounds endo-65 in good yields and good enantioselectivities (Scheme 17). ${ }^{42}$

Considering the concept of organocatalysis monitored in the firstly reported enantioselective 1,3-DC of azomethine ylides and alkenes, namely chiral hydrocinchonidine:AgF, ${ }^{35}$ hydroquinine 51 (6 mol\%, Figure 6) was found to be the best chiral base, together with AgOAc (to fix the geometry of the intermediate 1,3-dipole), in the synthesis of the chiral building blocks endo- $67 .{ }^{43}$ These products are the scaffolds for the elaboration of new active agents against the hepatitis $\mathrm{C}$ virus (HCV) ${ }^{44}$ Although chemical yields were very good, the enantioselection was moderate ( $74 \%$ ee) (Scheme 18 , and Table 1, entry 1 ). In fact, a further 1,1'-binaphthyl- 2,2'-dihydrogen phosphate assisted chiral resolution of 67 was required in order to obtain pure compound endo-66 with a $99.8 \% e e e^{43}$

However, the first enantioselective synthesis of the fivemembered core of these structures was performed by using the chiral metal complex formed from phosphoramidite $\left(S_{\mathrm{a}}, R, R\right)$-11 (Figure 3) and $\mathrm{AgClO}_{4}$ (both in $5 \mathrm{~mol} \%$ ) as catalyst. The reaction performed at $-20^{\circ} \mathrm{C}$ furnishes a good yield in compound endo- $67\left(\mathrm{X}=\mathrm{CH}, \mathrm{R}^{1}=\mathrm{Me}, \mathrm{R}^{2}=t \mathrm{Bu}\right)$ with a high enantioselection (Scheme 18, and Table 1, entry 2). In this work, the synthesis of enantiomerically enriched product $\mathbf{6 8}(82 \% e e)$ was also reported after amidation and double hydrolytic sequence involving TFA $/ 0^{\circ} \mathrm{C}$ followed by treatment with $\mathrm{KOH}-\mathrm{MeOH} / 80^{\circ} \mathrm{C} . .^{14,45}$ The Box ligand $\mathbf{3 3 b}$ and calcium isopropoxide formed a chiral complex, which was used to catalyse the process either at -44 or $-30{ }^{\circ} \mathrm{C}$ in THF as solvent. Yields are high and the enantioselectivities are the highest reported to date for compound $\mathbf{6 7}$ (85 and $88 \%$ ee) (Scheme 18 and Table 1, entries 3 and 4). ${ }^{30}$

According to the results described, a clear comparison can be established between organocatalysed and chiral Lewis-acid catalysed 1,3-DC process in the synthesis of cycloadducts 67 . The procedure involving chiral metal complexes was found much more advantageous from the operational and economical points of view (any additional

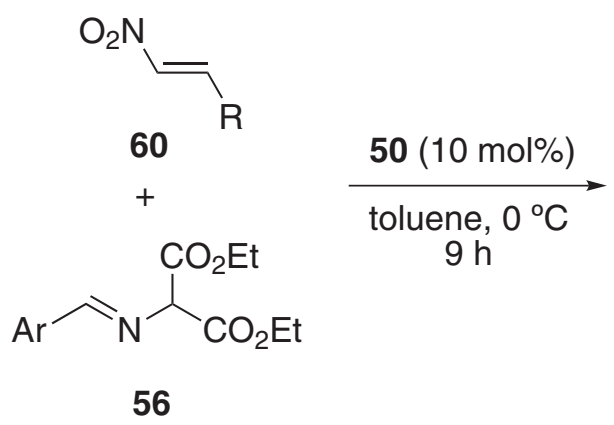

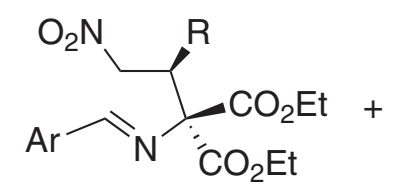

64

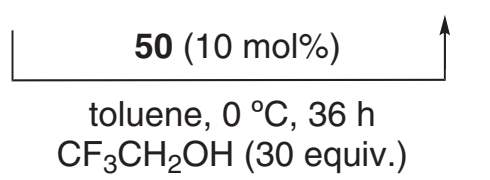

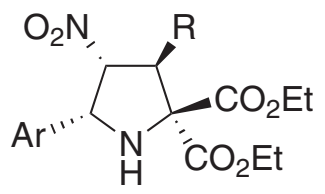

endo-65

$(72-86 \%)$

(>99:1 endo:exo)

(up to $92 \%$ ee)

Scheme 17.

Table 1. Catalytic enantioselective synthesis of compounds 67

\begin{tabular}{|c|c|c|c|c|c|c|c|c|c|}
\hline Entry & $\mathrm{X}$ & $\mathrm{R}^{1}$ & $\mathrm{R}^{2}$ & Salt $^{\mathrm{a}}$ & $\mathrm{L}^{\mathrm{a}}$ & Base & $\mathrm{T}\left({ }^{\circ} \mathrm{C}\right)$ & Yield $(\%)^{\mathrm{b}}$ & $e e(\%)$ \\
\hline $1^{44}$ & $\mathrm{~N}$ & $t \mathrm{Bu}$ & $\mathrm{Me}$ & $\begin{array}{l}\mathrm{AgOAc} \\
\text { (3) }\end{array}$ & $\begin{array}{l}51 \\
(6)\end{array}$ & - & 0 or -10 & 84 & 74 \\
\hline $2^{14}$ & $\mathrm{CH}$ & $\mathrm{Me}$ & $t \mathrm{Bu}$ & $\begin{array}{c}\mathrm{AgClO}_{4} \\
(5)\end{array}$ & $\begin{array}{l}\mathbf{1 1} \\
(5)\end{array}$ & $\begin{array}{c}\mathrm{Et}_{3} \mathrm{~N} \\
(5)\end{array}$ & -20 & 70 & 82 \\
\hline $3^{30}$ & $\mathrm{CH}$ & $t \mathrm{Bu}$ & $t \mathrm{Bu}$ & $\begin{array}{l}\mathrm{Ca}(\mathrm{O} i \mathrm{Pr})_{4} \\
\quad(10)\end{array}$ & $\begin{array}{c}33 \mathbf{b} \\
(10)\end{array}$ & - & -44 & 83 & $85^{\mathrm{c}}$ \\
\hline $4^{30}$ & $\mathrm{~N}$ & $t \mathrm{Bu}$ & $t \mathrm{Bu}$ & $\begin{array}{c}\mathrm{Ca}(\mathrm{O} i \mathrm{Pr})_{4} \\
(10)\end{array}$ & $\begin{array}{l}33 \mathbf{b} \\
(10)\end{array}$ & - & -30 & 83 & $88^{\mathrm{c}}$ \\
\hline
\end{tabular}

${ }^{\mathrm{a} I n}$ brackets (x, y or z mol\%); b ${ }^{\text {Isolated yield; }}$ ent-67 was obtained. 

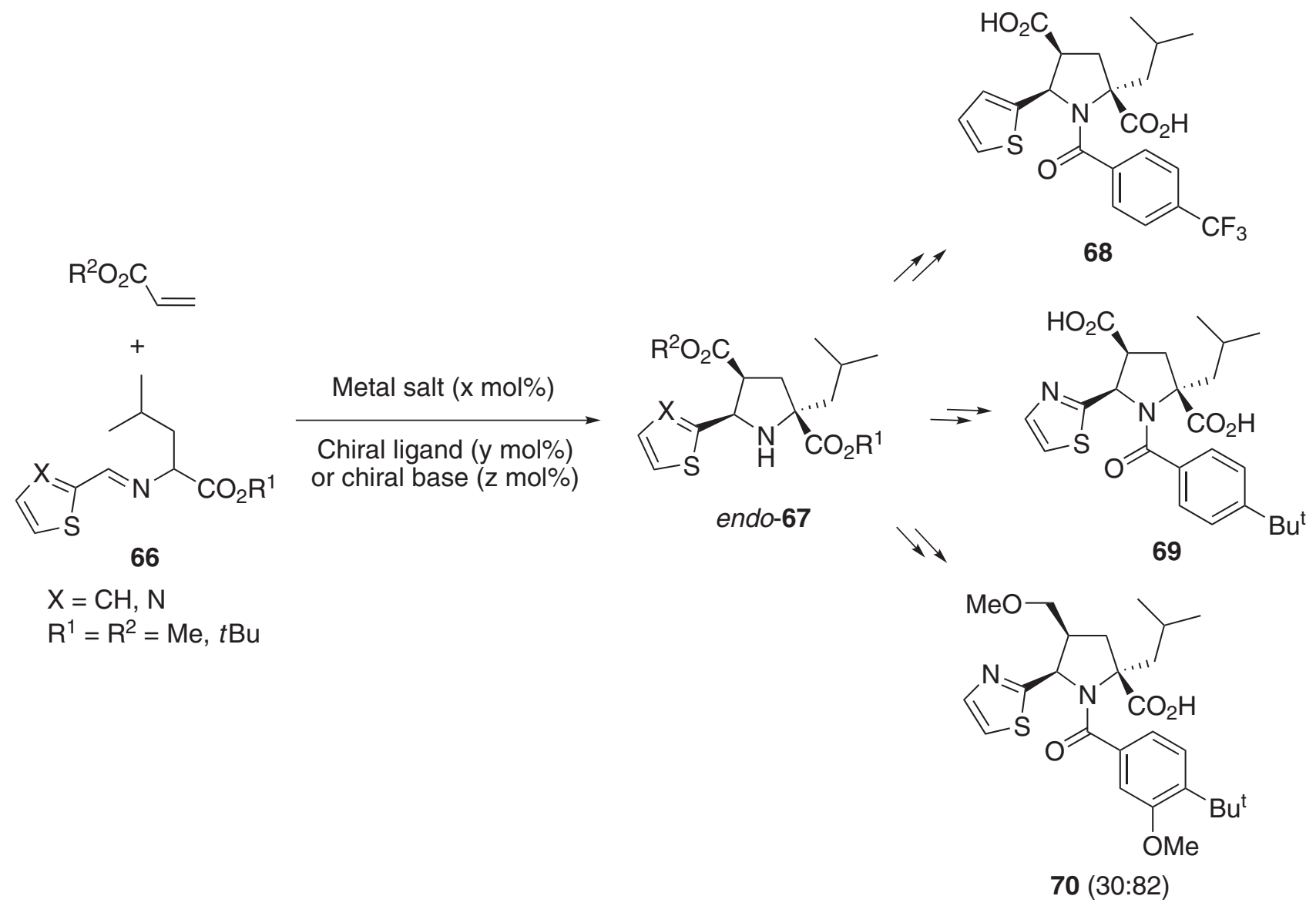

Scheme 18.

optical resolution was needed and the low cost of the calcium salt is evident) and the enantioselectivities are the highest reported to date.

An acid-base dual-functional catalysis using the axially chiral guanidine 52 (2 mol\%) was studied in the model 1,3-DC of azomethine ylides derived from starting material $5\left(\mathrm{R}^{1}=\mathrm{H}, \mathrm{R}^{2}=\mathrm{Me}\right)$ with dialkyl maleates has been reported. ${ }^{46}$ The stereochemistry obtained was the represented by compounds ent-endo-6 (Scheme 3) and were isolated with high endo-diastereoselectivities (>98:2), in moderate to good yields (53-80\%), and notable enantioselectivities (59-91\% ee). Unfortunately, another dipolarophiles failed or gave raise cycloadducts with very poor optical purity. This dual mechanism was proposed on the basis of the double hydrogen bond formation between the organocatalyst and the dipole, and the soft activation of the maleate by the different electronic part of the guanidinium cation in the plausible transition state TS-V ${ }^{46}$

Evaluating the whole data presented in this section, the organocatalysts and the chiral metal complexes have completely different behaviours concerning the 1,3-dipole and dipolarophile. Organocatalysts, unless that their basicity is relatively high, require a very activated

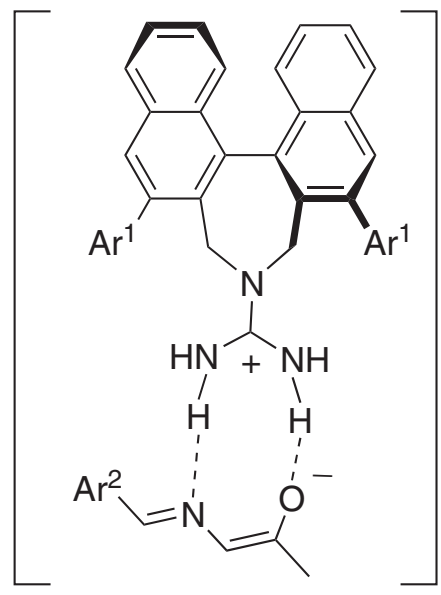

TS-5

arylideneiminomalonate $\mathbf{5 6}$ as 1,3-dipole precursor, and in many cases, their successful enantioselective process is limited to one dipolarophile. In this sense, structural limitations are notable and there are not wide-scope transformations at the moment. However, as it was described in the last example, these structural drawbacks could probably be overcome soon. By contrast, the chiral metal complex-catalysed enantioselective approach has 
been much more studied and the structural limitations are minimal, finding very interesting broad scopes for several chiral metal complexes. The fine tuning of the chiral ligand coordinated to the cation internal sphere allows to induce highest enantioselections, even being possible to modify the transition state to furnish the opposite configuration in the final product. The endo:exo ratio can be selected by adding the appropriate chiral metal complex, nevertheless only endo-products are mainly obtained from the organocatalysed 1,3-DC of azomethine ylides and alkenes. The metal-catalysed reactions are normally performed with lower catalyst loadings and shorter reaction times than those required for organocatalysed processes. Also, in organocatalysed transformations, the presence of additives is crucial for achieving very high enantioselections, and it is strongly dependent of the involved mechanism: this is not common in chiral metal complex-assisted asymmetric cycloadditions. The recovery and reutilisation has also been accomplished in the metal-catalysed 1,3-DC but much work must be still done in this area in the future.

\section{Nitrones}

The chemistry of nitrones $\mathbf{7 1}$, or azomethine oxides, is hugely varied, ${ }^{47}$ but it is ultimately dominated by their use as 1,3-dipoles for cycloaddition reactions. ${ }^{3,48}$ Although the most common 1,3-DC involving nitrones, is the formation of isoxazolidines $\mathbf{7 2}$ and $\mathbf{7 3}^{49}$ using different alkenes as dipolarophiles (Scheme 19), other different multiply bonded systems may also be used such as alkynes, allenes, isocyanates, nitriles, thiocarbonyls etc. The isoxazolidine adducts $\mathbf{7 2}$ and $\mathbf{7 3}$ contain up to three new stereogenic centres and the reaction products can be predictable according to the experiences, results, and frontier molecular orbital (FMO) theory. The E/Z-interconverting nitrones 71 reacted with electron-rich alkenes through a nitrone oxygen atom attack to the $\alpha$-position of the electron-rich alkene. However, this oxygen atom can also react at the $\beta$-position of the electron-poor alkenes (Scheme 19). Often, diastereomeric pairs of exo- and endo-adducts are formed under thermal conditions. Steric hindrance is of importance to control the approach of the alkenes towards the nitrones. Operating under metal-catalysed or organocatalysed processes, and working at low temperatures, the overall control of the absolute configuration of each stereogenic centre can be achieved, obtaining diastereoselectively the endo-cycloadduct, but with a non-predictable regioselectivity.

Once formed the isoxazolidine N-O bond may be reduced to a large series of products of potential interest such as 1,3-aminoalcohols. One of the reasons for the

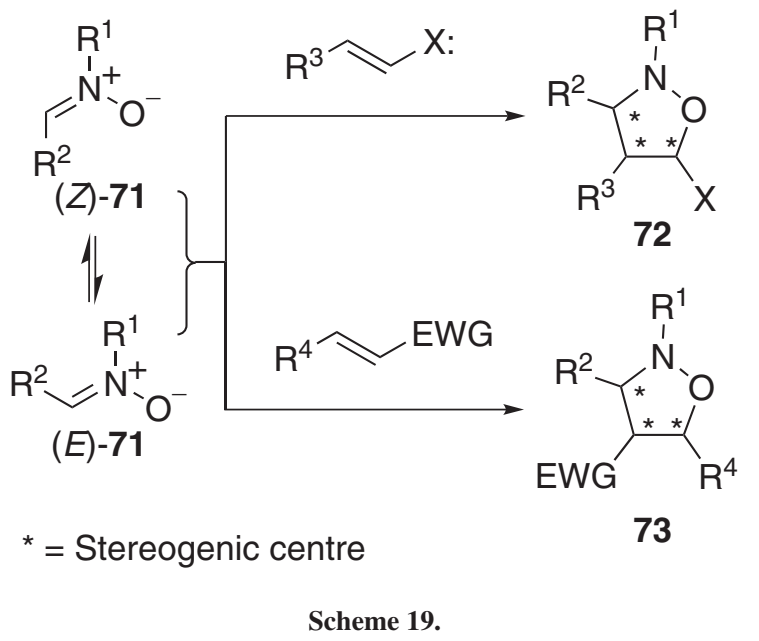

success of the synthetic application of nitrones is that, contrary to the majority of the other dipoles, most nitrones are stable compounds and do not require an in situ formation.

Metal-catalysed asymmetric 1,3-DC reactions involving nitrones became an important research field from the pioneering work of Jørgensen et al. ${ }^{50}$ in 1996. Continuing with the coverage, several examples have been found in the literature using the metal complexes shown in Figure 7.

A large series of chiral ruthenium(II) complexes 74-78 (Figure 7) have been tested ( $5 \mathrm{~mol} \%$ ) in 1,3-DC of nitrones 92-95 and methacrolein at different temperatures, the best results being presented in Scheme $20 .^{51}$ As it was reported, chiral complexes $\mathbf{7 4 b}$ and $\mathbf{7 4 c}$ gave the best 3,4:3,5 regioisomeric ratios, and compounds 97-99 were obtained as unique 3,5-regioisomers. In general, the enantioselectivities were very low, whilst chemical yields were very high or quantitative.

However, more important and attractive results were obtained with chiral iridium and rhodium complexes 79, and 80 (Figure 7). Particularly, iridium complex 79 $\left(10 \mathrm{~mol} \%, \mathrm{~L}=\right.$ enal ligand better than $\left.\mathrm{H}_{2} \mathrm{O}\right)$ was an adequate catalyst to perform the 1,3 -DC of the nitrone $\mathbf{9 2 b}$ with $\alpha, \beta$ unsaturated aldehydes 100 at $-25^{\circ} \mathrm{C}$. The product 3,4-endo101 was regio-, diastereo- and enantioselectively generated in very good yields and enantioselectivities (up to $94 \%$ ee), (Scheme 21, reaction a). Nitrone 95 exhibited a different regioselection depending on the used dipolarophile when the selected catalytic complex was $80(10 \mathrm{~mol} \%)$. The major 3,5-endo-adduct $\mathbf{1 0 2}$ was selectively generated from the intermediate akin to complex $\mathbf{8 0}\left(\mathrm{L}=\mathrm{H}_{2} \mathrm{O}\right)$, when the reaction was run with methacrolein ( $98 \%$ yield, and $73 \%$ ee) (Scheme 21, reaction b). Unlike the last optimised reaction conditions described, the reactions carried out with $\alpha, \beta$-unsaturated aldehydes 100 and nitrone 95 were better asymmetrically induced by chiral complex 80 (L = enal 


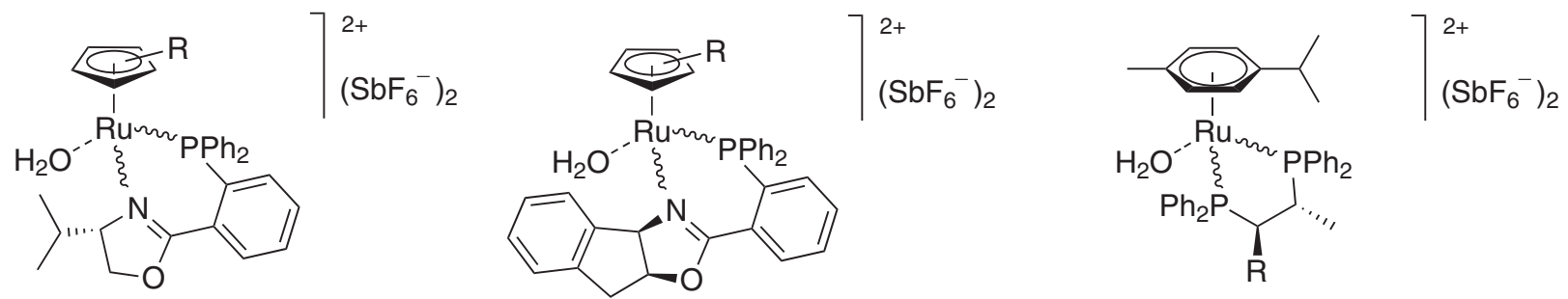

74a, $\mathrm{R}=\mathrm{H}$

74b, $\mathrm{R}=\mathrm{Me}_{6}$

74c, $\mathrm{R}=p$-MeiPr

$75 \mathrm{a}, \mathrm{R}=\mathrm{H}$

75b, $\mathrm{R}=\mathrm{Me}_{6}$

76a, $\mathrm{R}=\mathrm{H}$

75c, $\mathrm{R}=p-\mathrm{Me} i \mathrm{Pr}$

75b, $\mathrm{R}=\mathrm{Me}$

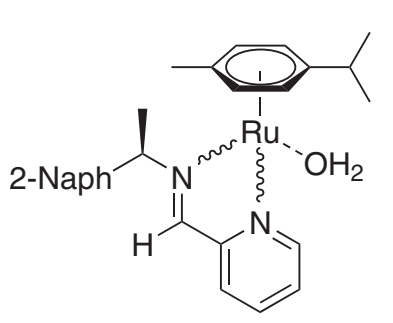

77<smiles>[SbH3]</smiles>

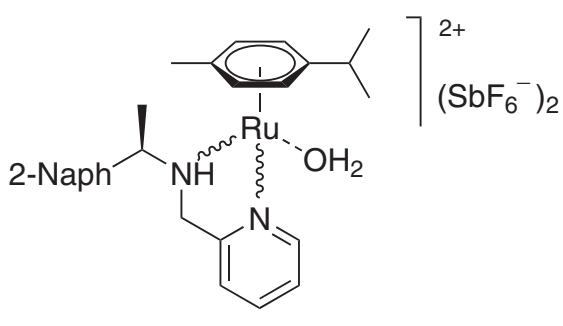

78

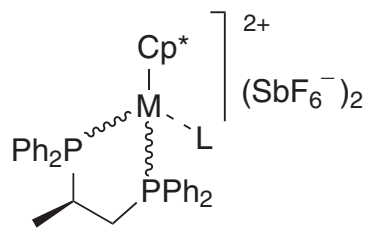

79, $M=I r$

80, $M=R h$<smiles>[R]C=C([R])C(=O)[OH+]O[CH]</smiles>

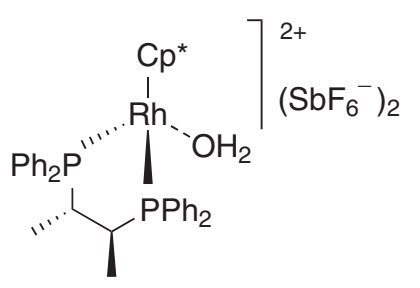

81

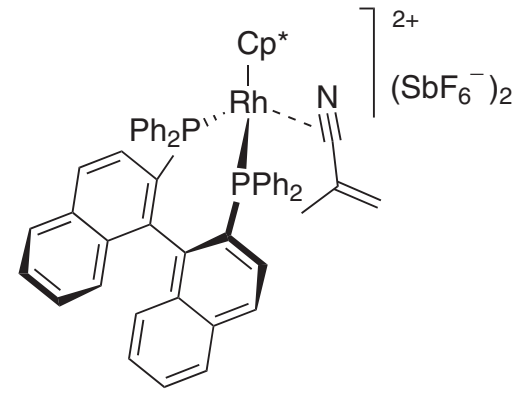

82

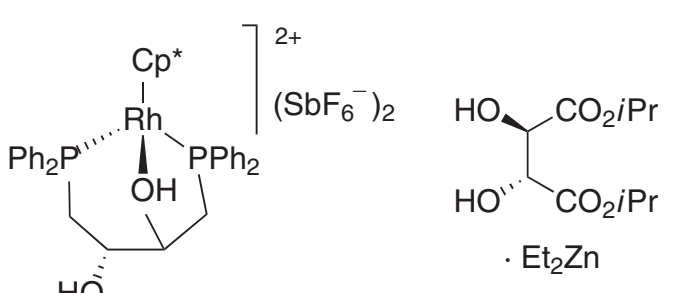

83
84

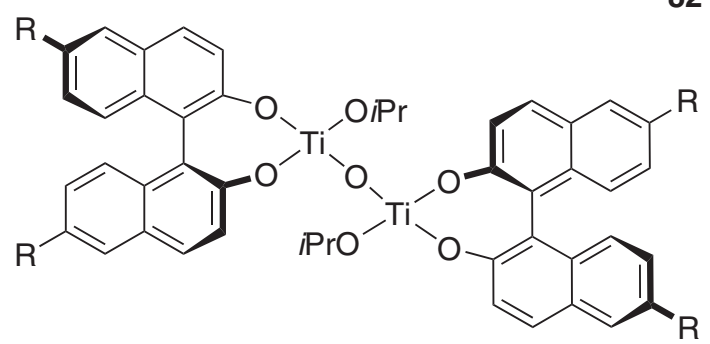

85a, $\mathrm{R}=\mathrm{H} \quad 85 \mathrm{~b}, \mathrm{R}=\mathrm{CF}_{3} \quad 85 \mathrm{c}, \mathrm{R}=\mathrm{Cl}$

$85 \mathrm{e}, \mathrm{R}=1$<smiles>CC1(C)C2=C(OCC2Br)N2C[C@H](Cc3ccccc3)CN21</smiles>

86<smiles>Cl[Ge]1OC2OC(c3ccccc3)OC2C(c2ccccc2)C(c2ccccc2)(c2ccccc2)O1</smiles>

87<smiles>CC1(C)C2=C(OC(c3ccccc3)C2c2ccccc2)N(C([O-])OCc2ccccc2)C1c1ccccc1</smiles>

88

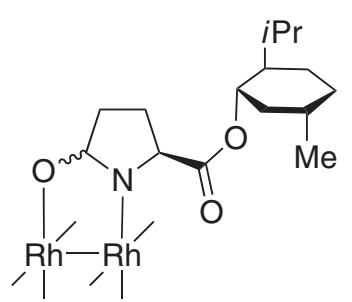

89

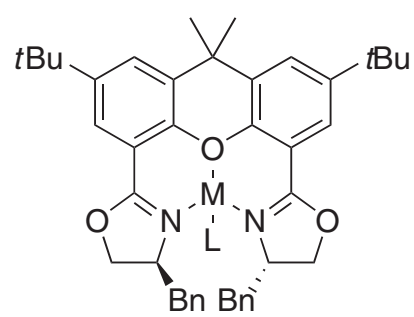

90a, $\mathrm{M}=\mathrm{Mg}\left(\mathrm{ClO}_{4}\right)_{2} \cdot 6 \mathrm{H}_{2} \mathrm{O}$ 90b, $\mathrm{M}=\mathrm{Mn}\left(\mathrm{ClO}_{4}\right)_{2} \cdot 6 \mathrm{H}_{2} \mathrm{O}$

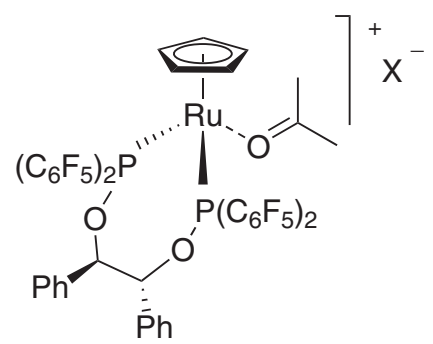

91a, $\mathrm{X}=\mathrm{BF}_{4}$ 91b, $\mathrm{X}=\mathrm{SbF}_{6}$

91c, $X=\mathrm{PF}_{6}$ 91d, $X=\left[3,5-\left(\mathrm{CF}_{3}\right)_{2} \mathrm{C}_{6} \mathrm{H}_{3}\right]_{4} \mathrm{~B}$

Figure 7. Chiral metal complexes evaluated in the 1,3-DC of nitrones and alkenes. 


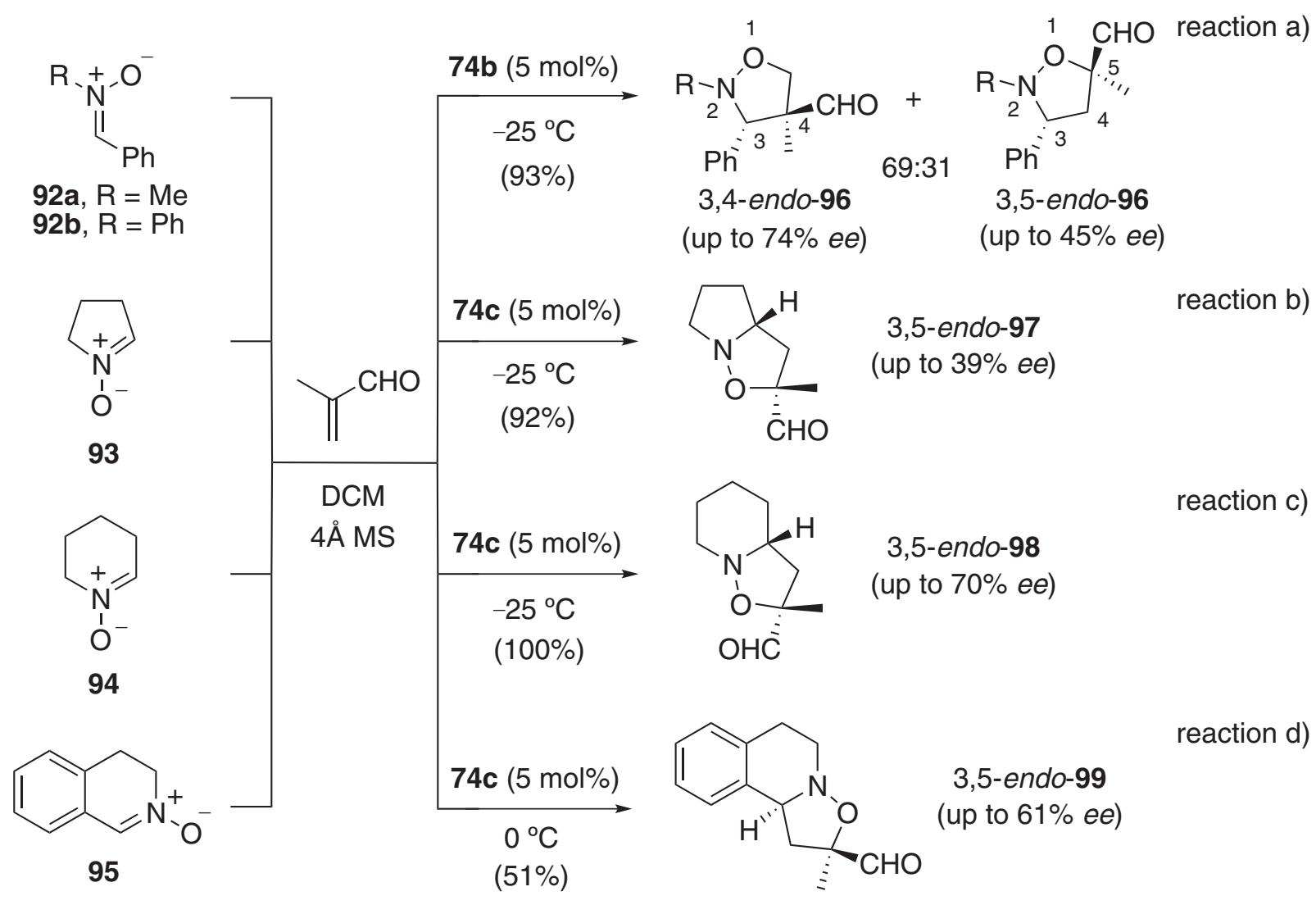

Scheme 20.

ligand), obtaining 3,4-endo-103 cycloadducts in very good yields and moderate to good enantioselections (Scheme 21, reaction c)..$^{52}$ The chiral environment of complexes 79-83 (Figure 7) was originated by the coordination with different diphosphanes, but the most synthetically useful complex was obtained when chiral 1,2-(diphenylphosphino) propane ( $R$-Prophos) was employed (complexes $\mathbf{7 9}$ and 80). Interestingly, complexes 81-83 gave better results than catalysts $\mathbf{7 9}$ and $\mathbf{8 0}$ in the 1,3-DC was surveyed with nitrones $92 \mathrm{~b}$, and 95 with a variety of dipolarophiles. ${ }^{52}$

An efficient regio-, diastereo-, and enantioselective transformation of several nitrones with allylic alcohols promoted by the chiral complex formed by diethylzinc and $(R, R)$-diisopropyl tartrate (DIPT) was achieved $\mathbf{8 4}$ (20 mol\%, Figure 7). ${ }^{53}$ In several examples, this reaction provided an approach to highly functionalised 3,5-transisoxazolidines with almost complete enantioselectivity (up to $83 \%$ yield and up to $>99 \%$ ee). But the scope of this transformation is very narrow because, when a structural modification of the starting materials was introduced, dramatic changes in the regio-, diastereo-, and enantioselections were observed.

Bistitanium species 85 (Figure 7) have been exploited as chiral Lewis acids in the 1,3-DC of nitrones $\mathbf{1 0 4}$ with methacrolein or $\alpha, \beta$-unsaturated aldehydes $\mathbf{1 0 0} .^{54}$ The catalyst $85 \mathbf{e}(\mathrm{R}=\mathrm{I}, 10 \mathrm{~mol} \%)$ promoted efficiently the cycloaddition of nitrones $\mathbf{1 0 4}$ with methacrolein in DCM at $0{ }^{\circ} \mathrm{C}$, affording isoxazolidines 3,5 -endo-105, in good chemical yields (48-80\%) and excellent enantioselectivities (up to $>99 \% e e$ ). The key of the success of this transformation was the introduction of bulky $\mathrm{N}$-substitution on the nitrone (benzhydryl group) in order to attenuate the undesired Lewis acid-nitrone complexation (Scheme 22, reaction a). This analogous structural detail was also considered in the 1,3 -DC with $\alpha, \beta$-unsaturated aldehydes $\mathbf{1 0 0}$. In this case, the formyl group had to be reduced in situ with $\mathrm{NaBH}_{4}$ to avoid undesirable epimerisations. The endo-3,4-cycloadducts 106 were finally isolated in good to excellent both chemical yields (83-99\%), and enantioselectivities (81-98\% ee) (Scheme 22, reaction b). Cycloadducts 106 were transformed into enantiomerically pure $\beta$-amino esters after three conventional steps in $43 \%$ overall yield (from 106). ${ }^{54}$

When copper(II) and titanium(IV) complexes 86 and 87 (Figure 7), were employed as catalysts (25 mol\% loading) in the 1,3-DC of nitrones $\mathbf{9 2 \mathbf { b }}$ and acryloyl derivatives, the results were very poor in terms of the regio-, diastereo- and enantioselectivity, showing the transformation a narrow scope. ${ }^{55,56}$ Fortunately, modification of chiral complex $\mathbf{8 6}$ 


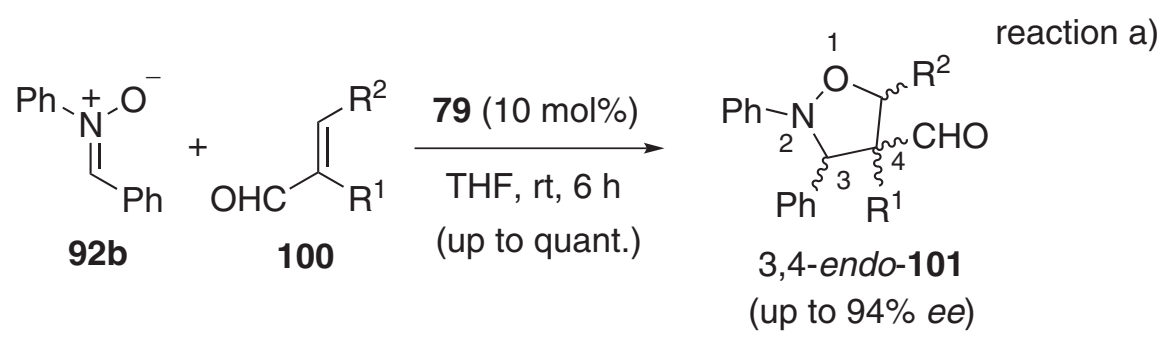<smiles>O[N+]1=Cc2ccccc2CC1</smiles><smiles>C=C(C)C#N</smiles><smiles>[O-][N+]1=Cc2ccccc2CC1</smiles><smiles>[R]/C=C(/[R])[O-]</smiles>

$80(10 \mathrm{~mol} \%)$ THF, rt, $24 \mathrm{~h}$

(98\%)<smiles>C[C@]1(C#N)C[C@@H]2c3ccccc3CCN2O1</smiles>

3,5-endo-102

(73\% ee)

reaction c)

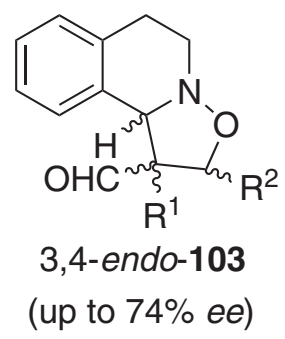

$80(10 \mathrm{~mol} \%)$

THF, rt, $24 \mathrm{~h}$

(up to quant.)

reaction b)

Scheme 21.<smiles>[R]C=[N+]([O-])C(c1ccccc1)c1ccccc1</smiles>

104

(48-80\%)<smiles>[R]C1N(C(c2ccccc2)c2ccccc2)OC[C@]1(C)C=O</smiles>

\section{3,4-endo-105}

(up to $99 \%$ ee)

reaction b)

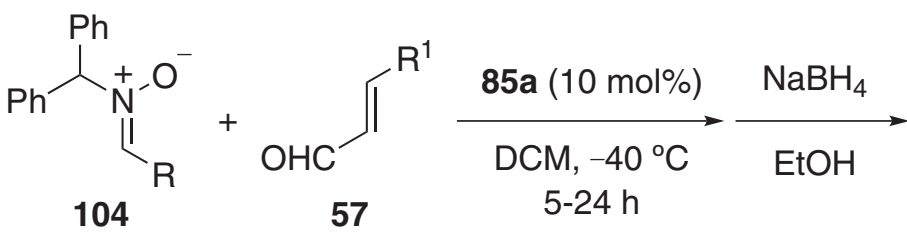

(83-89\%)<smiles>[R]C(N)C(CO)C(OC)OC</smiles>

107

Scheme 22.

to furnish the copper(II) complex $\mathbf{8 8}$ (Figure 7), resulted in improved catalytic activity in the 1,3-DC of nitrones $\mathbf{9 2}$ with enones 108. The reaction proceeded with a $10 \mathrm{~mol} \%$ catalyst loading, in $\mathrm{THF}$, at $0{ }^{\circ} \mathrm{C}$, affording regio- (only the 3,4-regioisomer), diastereo- (> 91:1 endo:exo ratio), and enantioselectively (up to $99 \%$ ee) the isoxazolidines $\mathbf{1 0 9}$ 
in very good yields (65-92\%) (Scheme 23). According to the authors, and based on the observed enantioselectivity, the $s$-trans-enone template was accommodated in the intermediate complex $\mathbf{1 1 0}$ by a $\pi-\pi$ stabilisation through a phenyl group. This interaction blocked the approach of the dipolarophile by the $R e$-face of the $\alpha$-carbon-carbon double bond. ${ }^{57}$

The new generation of cationic chiral dirhodium carboxamidates $\mathbf{8 9}$ (Figure 7) were tested as catalysts in the reaction depicted on reaction a in the Scheme 20. The yields were good (50-90\%) and the enantioselections were, in some cases, very important (up to $94 \%$ ee). Unfortunately, the isolated mixtures of both 3,4- and 3,5-endo regioisomers 96 could not be avoided. ${ }^{58}$

Xabox-Bn-MgII 90a, and Xabox-Bn-Mn ${ }^{\text {II }}$ 90b complexes (Figure 7) (10 mol\%) were found to be efficient catalysts in the 1,3-DC of nitrones 92 and $N$-acyloxazolidin2-ones 111. ${ }^{59}$ Although in several reactions a relative high proportion of exo-cycloadduct $\mathbf{1 1 2}$ was obtained, this problem could be minimised by replacing the magnesium central atom by manganese or vice-versa. Chemical yields, regio-, diastereo-, and enantioselections were quite high, as it is shown in Scheme 24.

Again, the model reaction drawn in reaction a of the Scheme 20 was employed to evaluate the catalytic activity of chiral complexes 91 (Figure 7) (5 mol\%). In these examples, as it was described in the above mentioned reaction promoted by catalysts $\mathbf{8 9}$, the major 3,5-endoadduct 96 was impurified with very important amounts of its 3,4-endo-96 regioisomer. Chemical yields were high (7795\%) and the enantioselectivity moderate to high (44-94\%) when the procedure took place in DCM at -10 to $-20^{\circ} \mathrm{C} .{ }^{60}$<smiles>[R]C=CC(=O)C[Po]=[Pt]</smiles><smiles>[R]C1ON([R])[C@@H](C(=O)C[PoH]=O)[C@@H]1P</smiles>

3,4-endo-109 (>99:1 endo:exo )

(up to $99 \%$ ee)

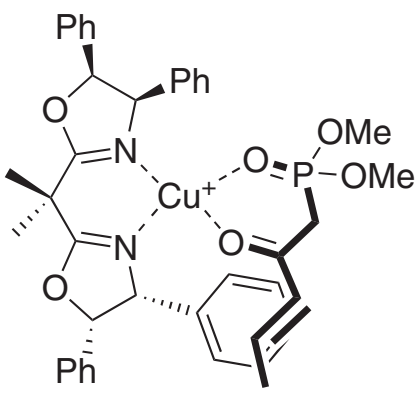

110

Scheme 23.<smiles>[R]C=CC(=O)N1CCOC1=O</smiles><smiles>[R][C@H]1[C@@H](C(=O)N2CCOC2=O)CON1[R]</smiles>

3,4-endo-112

(up tp >99:1 endo:exo )

(up to $96 \%$ ee)

Scheme 24. 
<smiles>[Al]NC(=S)N[C@H]1CCCC[C@H]1n1c(Br)ccc1Br</smiles>

113<smiles>CCNP(=O)(Oc1cc2ccccc2cc1Br)Oc1c(Br)cc2ccccc2c1-c1ccccc1</smiles>

114<smiles>CS(=O)(=O)c1ccccc1</smiles>

47<smiles>NC(Cc1ccccc1)C(=O)Nc1ccc2ccccc2c1-c1c(NC(=O)C(N)Cc2ccccc2)ccc2ccccc12</smiles>

115<smiles>CC(C)c1cc([Al])cc(C(C)C)c1CC=[Te]</smiles>

Figure 8. Organocatalysts essayed in the 1,3-DC of nitrones and alkenes.

The organocatalysed reactions involving cycloadditions between nitrones and alkenes have been recently mediated by the organocatalysts shown in Figure 8.

The thiourea derivative $\mathbf{1 1 3}$ (Figure 8) promoted the first organocatalytic stereoselective 1,3-DC of nitrones and $\beta$-alkyl nitroolefins. ${ }^{61}$ In general, a $10 \mathrm{~mol} \%$ of catalyst 113 in tert-butyl methyl ether (MTBE) as solvent, at $0{ }^{\circ} \mathrm{C}$ for 6 days, gave raise to chiral oxazolidines 3,4-exo-116 in good chemical yields and high enantioselections (80-88\% ee), with excellent exo-diastereoselectivities (> 99:1 exo:endo ratio) (Scheme 25).

The chiral $N$-triflyl phosphoramide 114 (Figure 8 ) was used in the 1,3-DC of nitrones $\mathbf{9 2}$ and ethyl vinyl ether. $5 \mathrm{~mol} \%$ of this air stable organocatalyst was enough to lead to complete the reaction in $1 \mathrm{~h}$, obtaining products 3,5-endo-117 (74\%-quant. yield, and up to $93 \%$ ee) ${ }^{62}$ The endo-selectivity of this cycloaddition was also important (up to 97:3 endo:exo ratio) taking into account the high electron density of the employed dipolarophile (Scheme 26). The proposed mechanism that explained the elevated stereocontrol is based on dominant secondary $\pi$-orbital interactions deduced by computational calculations.

In addition to 1,3-DC of azomethine ylides and alkenes, organocatalyst $47(10 \mathrm{~mol} \%)$ (Figure 8$)$, has also been reported for the cycloaddition of nitrones 92 with $\alpha, \beta$-unsaturated aldehydes 57 (Scheme 22, reaction b) ${ }^{63}$ The reaction proceeded in toluene at room temperature in around $24 \mathrm{~h}$. The resulting 3,4-ent-endo-cycloadducts (relative to the structure of compound 106) did not epimerise at all, and for this reason the formyl group was not necessary to be reduced. The enantioselectivity $(88-96 \% e e)$ was higher than the one for the analogous obtained in the same reaction catalysed by chiral complex 85 (Scheme 22, reaction b).

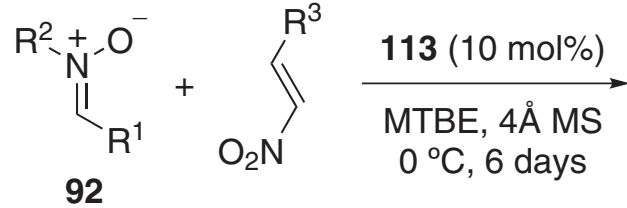

60

$(54-93 \%)$
Scheme 25 .<smiles>[R7]C=[N+]([R7])[O-]</smiles>

92<smiles>[R]C1[C@H]([N+](=O)[O-])[C@@H](P)ON1[R]</smiles>

\section{3,4-exo-116}

$(80-88 \%$ ee)

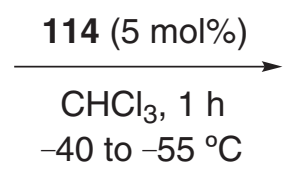

(74\%-quant.)<smiles>[R]C1C[C@H](OCC)ON1[R]</smiles>

3,5-endo-117

(up to $93 \%$ ee)

Scheme 26. 
In both transformations the diastereoselectivity was very high (up to 99:1 endo:exo ratio). ${ }^{63}$

By contrast, the analogous reaction represented in reaction b of Scheme 22, performed with Binam-diamides 115 (Figure 8) (10 mol\%), in nitromethane as solvent at $0{ }^{\circ} \mathrm{C}$, afforded mixtures of endo:exo cycloadducts with moderate to good enantioselections $(61-95 \%$ ee $)$ but never improving the results obtained in this reaction organocatalysed by the prolinol derivative $\mathbf{4 7} .^{64}$

Evaluating all these results described in the 1,3-DC with nitrones, we can observe chiral metal complexes and organocatalysts, do not have a preference for a determined 3,4- or 3,5-regioisomer. However the endo-diasteresoselectivity achieved was almost total independently of the metal used, whilst major endo- or exo-cycloadducts can be obtained depending of the organocatalyst employed. In other words, it is possible to select the catalyst to generate 3,4- or 3,5-regioisomers of each exo- or endo-cycloadducts with elevated stereocontrol. A very important feature of this particular cycloaddition is that the electron-rich alkenes, in contrast to the preference of the azomethine ylides, can be efficiently employed as dipolarophiles with nitrones. However, some parameters must be improved, such as: (i) the amount of the catalyst employed, which is rather high, and (ii) a wide scope of the catalyst, because most of the 1,3-DCs described in this section are restricted to one or a small number of dipolarophiles.

\section{Nitrile Oxides}

Nitrile oxides 119 are prone to dimerise or polymerise, especially upon heating. With the aim to avoid the dimerisation process, these 1,3-dipoles must be generated in situ. There are many methods described for their preparation, ${ }^{3}$ dehydrohalogenation of hydroxymoyl chlorides 118 and dehydration of nitroalkanes being the most frequently used strategies. In this section all the nitrile oxides were obtained following the dehydrohalogenation route. The regioselectivity of the 1,3-DC of nitrile oxides and alkenes or alkynes is easily predictable. For monosubstituted alkenes and electrophilic olefins the major regioisomer are isoxazoles or isoxazolines ${ }^{49} \mathbf{1 2 0 a}$ and 120b are, respectively, isolated as pure compounds (Scheme 27). At maximum, only two stereogenic centres can be generated employing a catalytic enantioselective version of this reaction.

In 2004 the first chiral metal-catalysed 1,3-DC involving nitrile oxides and electron-deficient alkenes was published. ${ }^{65}$ Following this seminal work, several attempts were made, including also cycloadditions catalysed by chiral metal complexes added in stoichiometric amounts. ${ }^{66,67}$ To the best of our knowledge, any organocatalysed 1,3-DC of nitrile oxides and alkenes have been reported yet, and the most relevant Lewis acids are covered in this review and represented in Figure 9.

The catalytic chiral ruthenium(I) complex 91b (Figure 9), already described in 1,3-DC between nitrones and alkenes, was employed (5 mol\%) in the reaction of nitrile oxides $\mathbf{1 2 5}$ and methacrolein. The reaction was completed in DCM, at $-5{ }^{\circ} \mathrm{C}$ after $16-47 \mathrm{~h}$, with slow addition of the nitrile oxide $(10 \mathrm{~h})$ to the solution containing all the reactants. The further reduction of the formyl group was carried out immediately to avoid epimerisations. The 3,5-disubstituted isoxazolines $\mathbf{1 2 6}$ were obtained in moderate-good yields (43-71\%), as single diastereoisomers (3,5-cycloadducts), with moderate to good enantioselections (63-93\% ee) (Scheme 28). ${ }^{60,68}$

The chiral complexes formed by ligands $\mathbf{1 2 1}$ and $\mathbf{1 2 2}$ with $\mathrm{Yb}(\mathrm{OTf})_{3}$ (Figure 9) were independently tested in the 1,3-DC of nitrile oxides $\mathbf{1 2 5}$ and the (Z)-allylic alcohol $\mathbf{1 2 7}$. In both reaction a and $b$ of the Scheme 29, almost equimolar amounts of isoxazolines 3,5-128 and 3,4-128 were isolated. The reaction catalysed by the complex 121- $\mathrm{Yb}(\mathrm{OTf})_{3}$ afforded lower yields and poorer enantioselectivities than the analogous reaction activated by the chiral complex

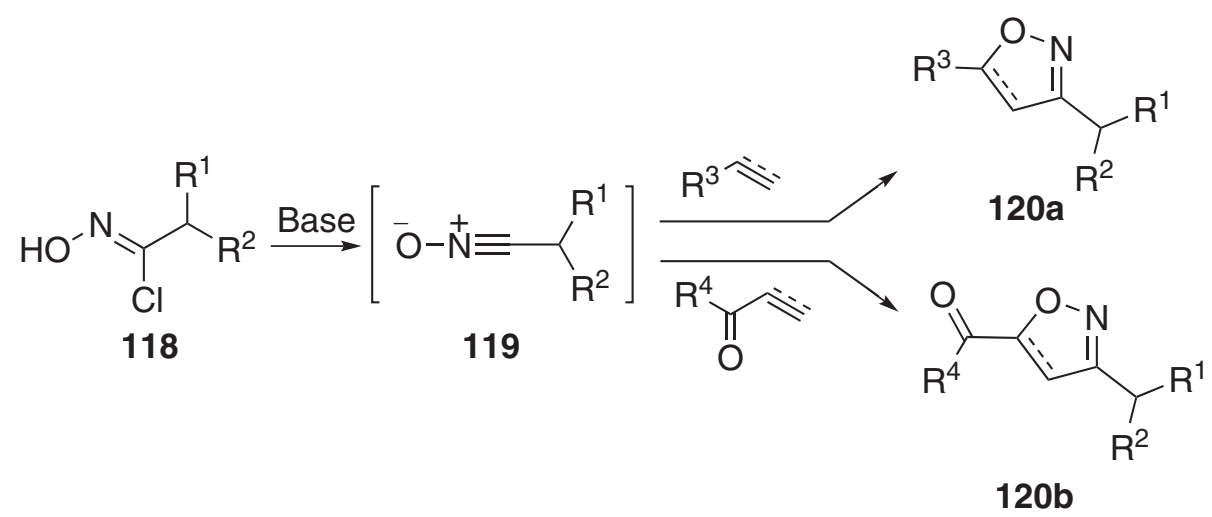

Scheme 27. 


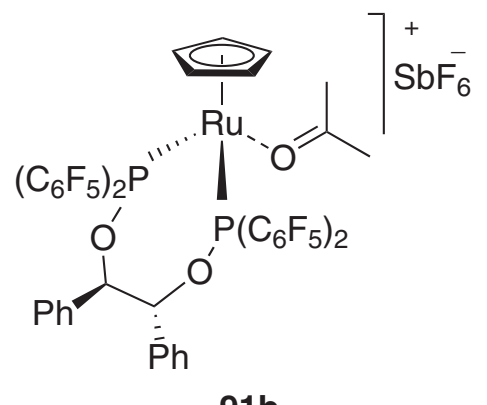

91b

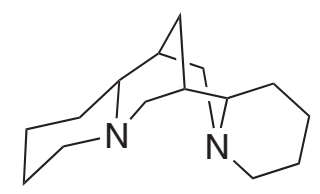

$121 / \mathrm{Yb}(\mathrm{OTf})_{3}$<smiles>Oc1ccc2ccccc2c1-c1c(O)ccc2ccccc12</smiles>

$122 / \mathrm{Yb}(\mathrm{OTf})_{3}$<smiles>[X]c1cc(C=Nc2ccc3ccccc3c2-c2c(N=Cc3cc([X])c4ccccc4n3)ccc3ccccc23)nc2ccccc12</smiles>

$X=3,5-x y l y l$

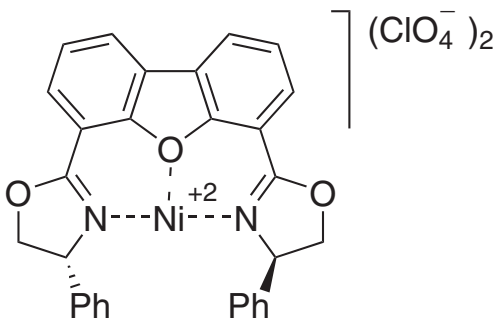

124

Figure 9. Defined chiral complexes or chiral ligand/metal salts combinations employed in the 1,3-DC of nitrile oxides and alkenes.

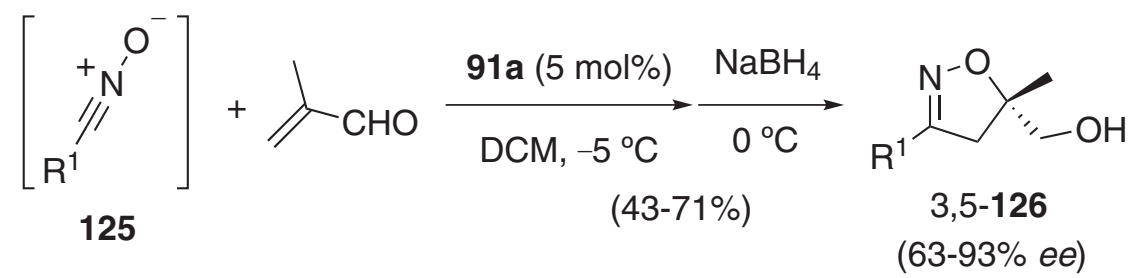

Scheme 28.

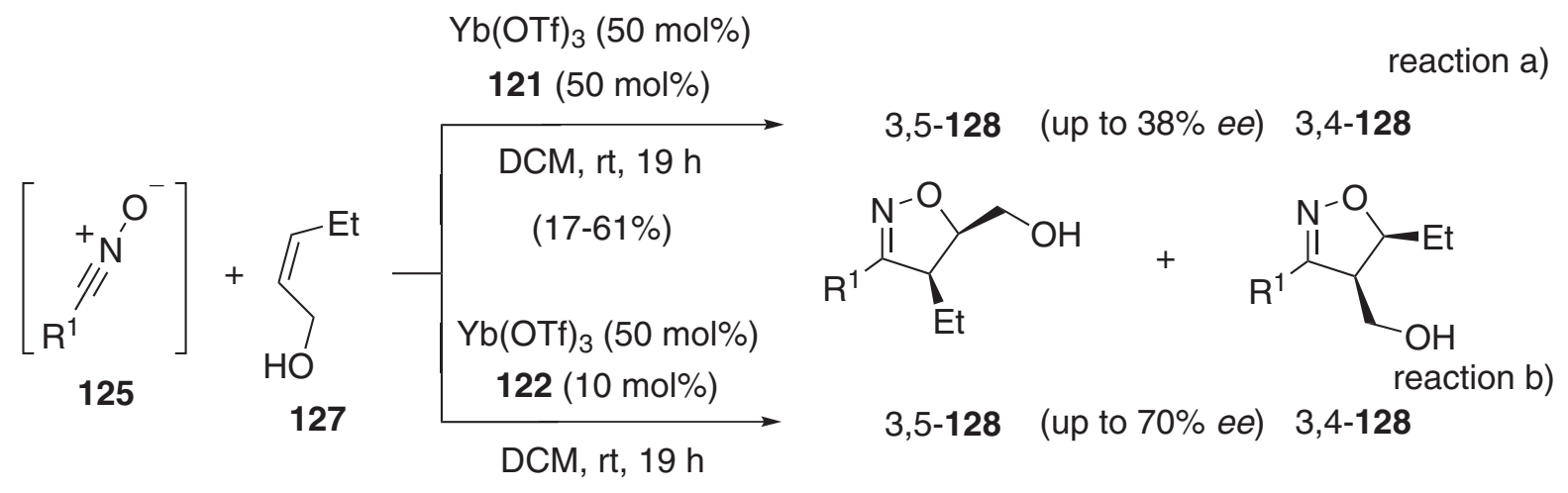

$(27-68 \%)$

Scheme 29.

122- $\mathrm{Yb}(\mathrm{OTf})_{3}$ (up to $70 \%$ ee) (Scheme 29). ${ }^{69,70} \mathrm{~A}$ similar behaviour, of these last two chiral complexes was exhibited in the reaction of nitrile oxides $\mathbf{1 2 5}$ and $\alpha, \beta$-unsaturated esters. ${ }^{69,70}$
The catalytic activity of nickel(II) ligated by $\mathbf{1 2 3}$ (Figure 9) (10-20 mol\%) was demonstrated in the 1,3-DC of nitrile oxides $\mathbf{1 2 5}$ and $\alpha, \beta$-unsaturated systems 129 (Scheme 30). ${ }^{71}$ In several examples, the regioisomeric 


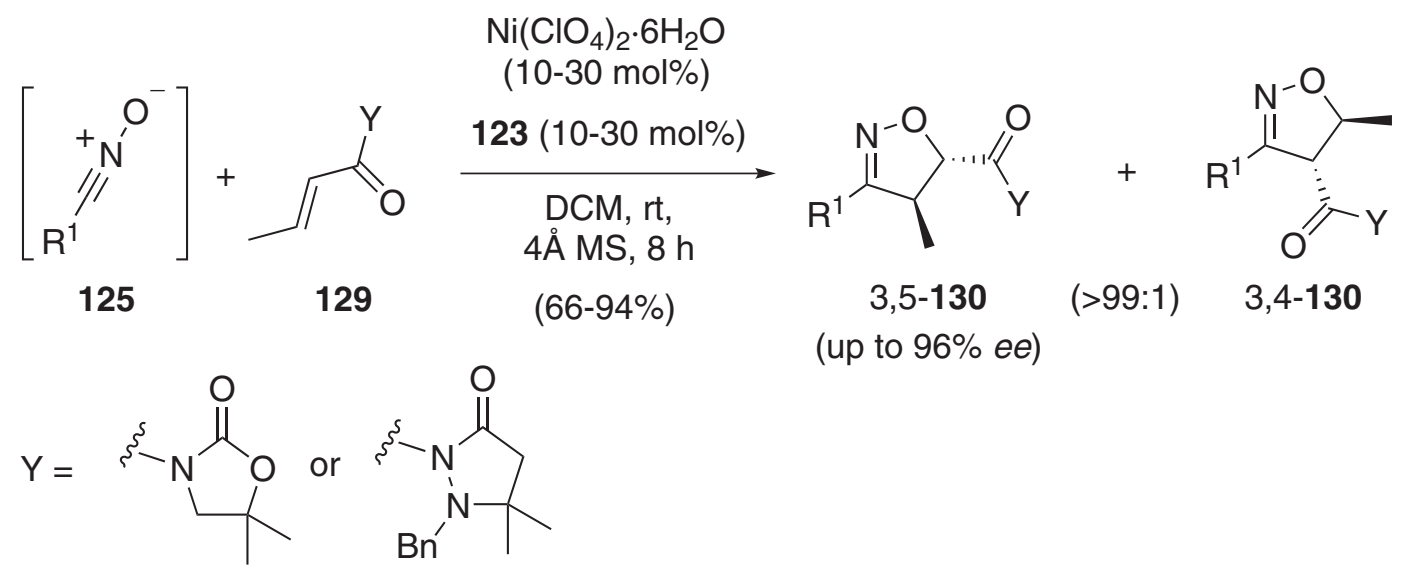

Scheme 30.

ratio could be inverted, but maintaining an elevated stereochemical control. The high level of asymmetric induction was attributable to the highly selective approach of the nitrile oxides towards the $\mathrm{Si}$ face of the proposed hexa-coordinated nickel(II) complex, whilst the Re-face attack was shielded by one of the xylylquinoline moieties.

Very recently, it has been regarded that nitrile oxides can be obtained from hydroxymoyl chlorides in the presence of $3 \AA$ or $4 \AA$ molecular sieves (MS) as mild solid bases. ${ }^{72}$ This property was immediately applied to the enantioselective synthesis of isoxazolines by adding slowly the mixture of compound $\mathbf{1 1 8}$ and the alkene $\mathbf{1 3 1}$ onto a mixture containing the chiral nickel(II) complex $124(10 \mathrm{~mol} \%)$ and $4 \AA \mathrm{MS}\left(500 \mathrm{mg} \mathrm{mmol}{ }^{-1}\right.$ of 118) ${ }^{72}$ The results obtained from this transformation were excellent just for a reduced set of examples (Scheme 31). Chemical yields and enantioselectivities for heterocycles $\mathbf{1 3 2}$ were very high (65-94\% and 90-98\% ee, respectively).

In general, the 1,3-DC of nitrile oxides afforded mainly 3,5-regioisomeric isoxazolines with rare examples generating amounts of 3,4-regioisomers. The chiral Lewis- acid control gave good enantioselections of heterocyclic compounds, perhaps, the catalyst amounts are too elevated in some cases and the reaction conditions have to be carefully checked to achieve the best results.

\section{Diazoalkanes and Carbonyl Ylides}

For a long time, diazo-compounds $\mathbf{1 3 3}$ have been one of the most synthetically useful classes of 1,3-dipoles because, in contrast to other 1,3-dipoles that are generated as transient species, they could be prepared and isolated in pure form. ${ }^{3}$ The cycloadditions with double or triple bonds (including heteroatoms) have been widely surveyed (Scheme 32). The reaction with electrophilic olefins occurred such as it is depicted in Scheme 32, the carbon atom reacted at the 4-position of the electrophile with almost total selectivity to yield pyrazoline or pyrazole derivatives 134 or $\mathbf{1 3 5}$. Nevertheless, some mixtures of regioisomers are obtained by reaction with electron-rich alkenes. In addition, the reaction of diazoalkanes with nitriles also gave good regioselectivities of the corresponding compounds 135 (Scheme 32).

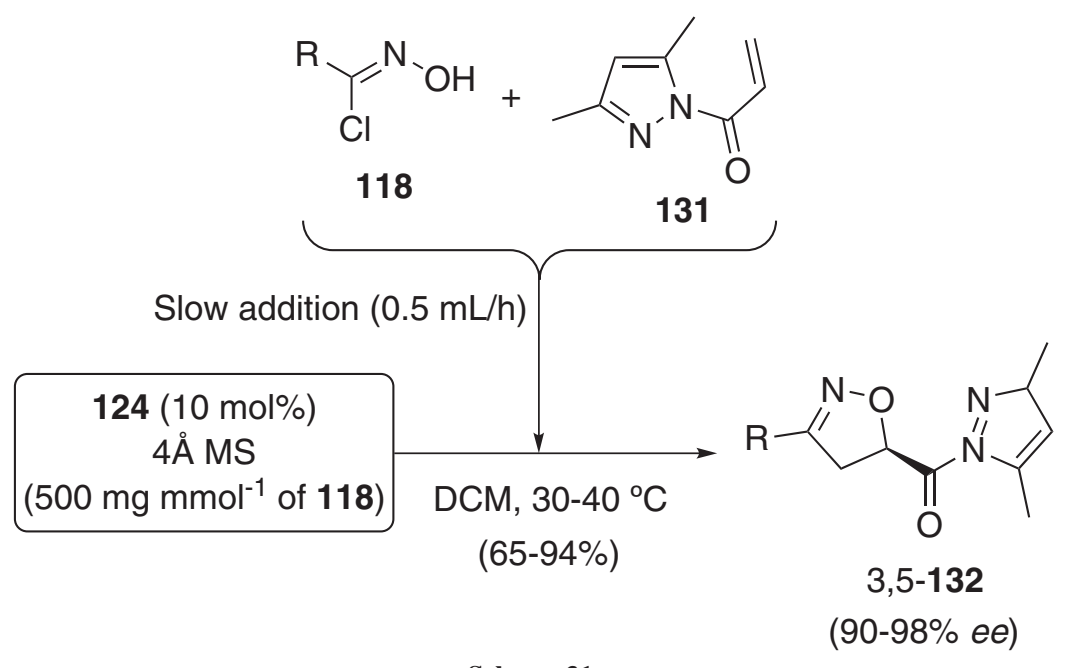

Scheme 31. 


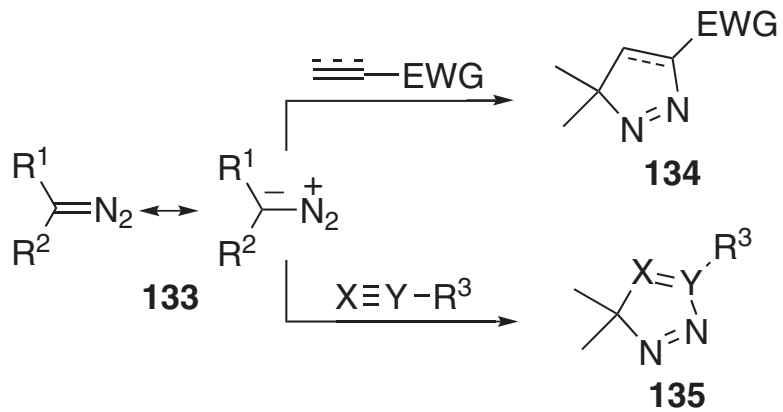

Scheme 32.

The employment of catalytic chiral metal complexes (Figure 10) in the 1,3-DC of diazocompounds and alkenes or alkynes constitutes a new emerging area because all the published contributions appeared in a three year period.

The first catalytic enantioselective 1,3-DC between diazoacetates 141 and substituted acroleins employed the chiral Binol-titanium(IV) complex 136 (10-50 mol\%, Figure 10). ${ }^{73}$ The reaction occurred in DCM at $-40{ }^{\circ} \mathrm{C}$ affording 2-pyrazolines 142 in good yield (52-85\%) and high enantioselections (81-95\% ee) (Scheme 33). The resulting compound was formed after a spontaneous double bond isomerisation in the pyrazoline ring due to the presence of the electron withdrawing group $\left(\mathrm{CO}_{2} \mathrm{R}^{1}\right)$ at the 3-position. This methodology was successfully applied to the synthesis of (-)-manzacidin A 143, which is an interesting an rare alkaloid found only sparingly in the nature.
Later on, a set of chiral catalytic complexes were used for achieving high enantioselections in processes involving diazoalkanes and carbonyl ylides (Figure 10). As an example, a method for the enantioselective synthesis of 2-pyrazolines $\mathbf{1 4 5}$ through a magnesium(II)-catalysed cycloaddition of $\alpha$-diazoesters 141 to $\alpha, \beta$-unsaturated pyrazolidinone imides 144 was reported. ${ }^{74}$ This synthesis allowed the introduction of several substituents in the dipole acceptor 144, but a higher amount of the chiral Lewis acid 137 was needed to achieve very good enantioselections (90-99\% ee) and high yields (52-91\%) for the pyrazoline 145 (Scheme 34), even when the reaction was performed at $50{ }^{\circ} \mathrm{C}$ for $48 \mathrm{~h}$. (-)-Manzacidin A $\mathbf{1 4 3}$ was further prepared from $\mathbf{1 4 5}$ as key intermediate.

In some particular examples, diazoalkanes can be transformed into carbonyl ylides as intermediate species, which are able to react with several dipolarophiles. 1-Diazo-5-phenylpentane-2,5-dione $\mathbf{1 4 6}$ was transformed into the corresponding rhodium carbene, which underwent an intramolecular attack by the oxygen atom to generate a fleeting carbonyl ylide 147. This reactive species was immediately trapped by aromatic aldehydes acting as dipolarophiles, yielding exclusively the exo-cycloadducts 148 in moderate yields (21-71\%) and relative good enantioselectivity (61-92\% ee) (Scheme 35 , reaction a). ${ }^{75}$ In order to improve chemical yields and enantioselectivities it was necessary to stabilise both the rhodium carbene and<smiles>CC(C)O[Te]1(OC(C)C)Oc2ccc3ccccc3c2-c2c(ccc3ccccc23)O1</smiles>

136<smiles></smiles>

139

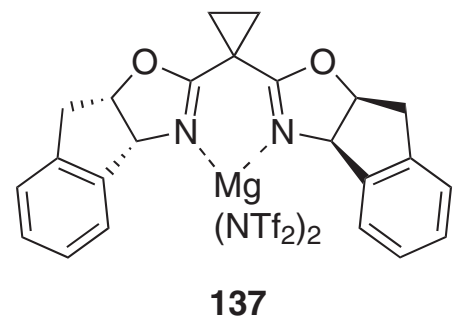

137<smiles>[X]c1cc(/C=N/c2ccc3ccccc3c2-c2c(/N=C/c3cc([X])c4ccccc4n3)ccc3ccccc23)nc2ccccc12</smiles>

$X=3,5-x y l y l$<smiles></smiles>

138

Figure 10. Defined chiral complexes or chiral ligand/metal salts combinations employed in the catalytic enantioselective 1,3-DC involving diazoalkanes and carbonyl ylides. 

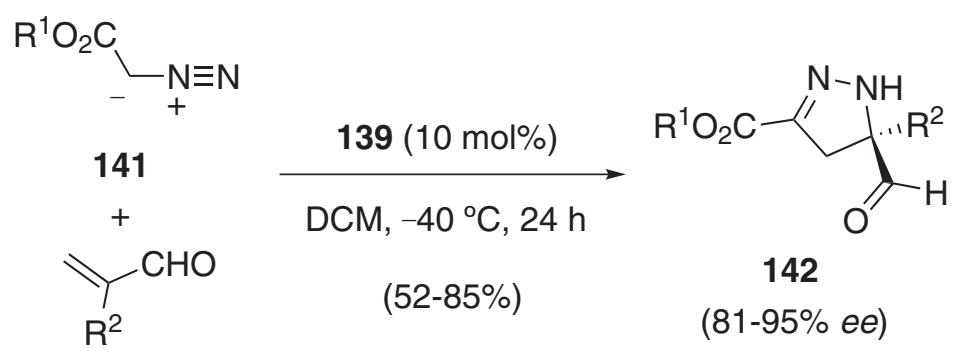<smiles>[R][Y]([H])(I)[I-]</smiles>

(-)-Manzacidin A

143

Scheme 33.
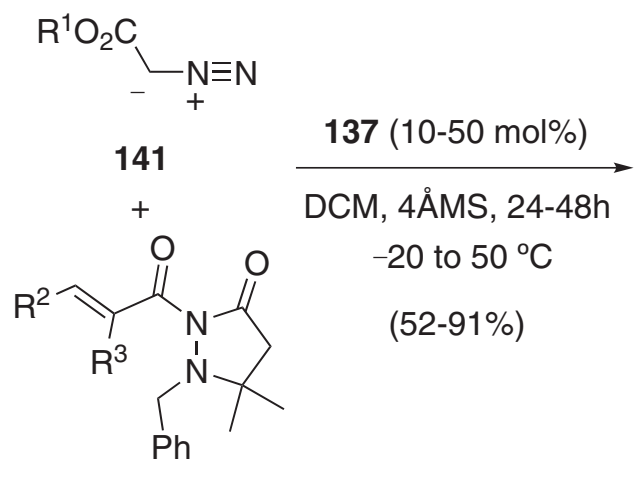<smiles>[R2]CC1([Y7])NN=C(C(=O)O[R2])C1[R]</smiles>

145

$(90-99 \%$ ee)

144

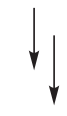

143

Scheme 34.

the carbonyl ylide. For this purpose, tert-butyl 2-diazo3,6-dioxoheptanoate 149 was selected as starting material in the domino rhodium carbene formation-cyclic carbonyl ylide generation-cycloaddition reaction catalysed by the chiral dirhodium complex 139 (Figure 10). Alkenes and alkynes reacted with the transient carbonyl ylide type 147 at room temperature to afford exclusively exocycloadducts 150 in very good yields (60-94\%) and excellent enantioselectivities (Scheme 35, reaction b). ${ }^{76}$ This rhodium-catalysed procedure was utilised in the asymmetric synthetic approach to the pentacyclic skeleton of Aspidosperma alkaloids. In this way, fused pentacyclic scaffold endo-151 was isolated in 43\% yield and and $66 \%$ ee. The reversal diastereoselection observed in this example was attributable to steric hindrance of part of the functional groups present in the precursor material. ${ }^{77}$ The intramolecular version of this reaction was evaluated with analogous starting compounds bearing the alkene moiety (dipolarophile) placed at the $\mathrm{R}^{1}$ substituent in molecules 149 at the appropriate distance. The rhodium complex 138 (Figure 10) (10 mol\%) was the best catalyst but the enantioselection of the process was very disappointing (up to $44 \%$ ee $)^{78}$

High levels of asymmetric induction were observed in the dipole-LUMO/dipolarophile-HOMO controlled cycloaddition reactions between 2-benzopyrilium-4enolates and vinyl ether derivatives. The difference between Schemes 35 and 36 was that a chiral Lewis acid, apart from the rhodium complex, was required to perform the cycloaddition step in Scheme 36, and consequently no domino sequence existed. Chiral nickel(II) complex derived from ligand $\mathbf{1 2 3}$ (Figure 9) (10 mol\%, Figure 10) proved to be the most suitable catalyst for the 1,3-DC initiated by the most stable carbene precursor $\mathbf{1 5 2}$, 
<smiles>N#CC(=O)CCC(=O)c1ccccc1</smiles>

146

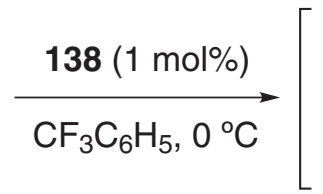

$\mathrm{CF}_{3} \mathrm{C}_{6} \mathrm{H}_{5}, 0^{\circ} \mathrm{C}$

(1)<smiles>O=C1CCC(c2ccccc2)=[O+]C1c1ccccc1</smiles>
147

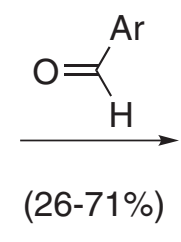

$(26-71 \%)$<smiles>O=C1CC[C@@]2(c3ccccc3)OC(Br)[C@@H]1O2</smiles>

exo-148

$(61-92 \%$ ee $)$

reaction $b)$<smiles>[R]C(=O)CCC(=O)C(C#N)(C#N)C(C)(C)C</smiles>

149

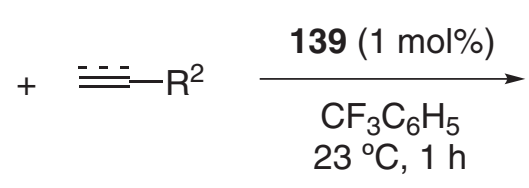

$(60-94 \%)$<smiles>[R][C]1CCC(=O)[C@@](C([R])=C)(C(=O)OC(C)(C)C)O1</smiles>

exo-150

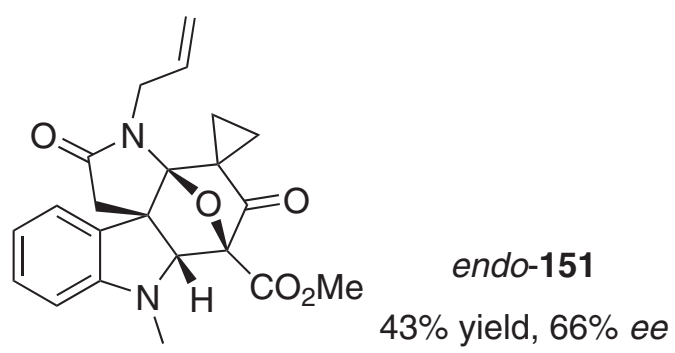

Scheme 35 .

yielding, after $1 \mathrm{~h}$ at room temperature, endo- $\mathbf{1 5 3}$ products as major diastereoisomers in good yields (78-96\%) and high enantioselectivities (77-97\% ee) (Scheme 36, reaction a) ${ }^{79}$ Nevertheless, when the reactions were performed with diazoalkanes 154, chiral complex 140 (10 mol\%) offered the best results for cycloadducts $\mathbf{1 5 5}$ (using dihydrofuran as dipolarophile) or $\mathbf{1 5 6}$ (if butyl vinyl ether was employed). These two different dipolarophiles exhibited contrary diastereoselections. Whilst dihydrofuran mainly afforded an endo-cycloadduct 155, butyl vinyl ether furnished the exo-cycloadduct 156 as major diastereoisomer. In both transformations the chemical yields were good but the enantioselections were modest (59 and 67\% ee, respectively) (Scheme 36, reaction b). ${ }^{79}$

Any comparison between organocatalysed process and chiral metal complex-catalysed reactions can be made dealing with 1,3-DC involving diazoalkanes or the elegant in situ generation of carbonyl ylides-1,3-DC domino process. The metal catalysts afforded preferentially endoadducts and both type of dipoles reacted with dipolarophiles different from electrophilic alkenes, such as electron-rich alkenes and alkynes, carbonyl groups, vinyl ethers, etc.

\section{Phosphonium-inner Salts}

In previous sections all the discussed 1,3-DCs afforded five-membered ring heterocycles in an enantioselective manner, but five membered carbocycles are very important systems due to their significance and utility in many scientific areas. From a series of elegant [3+2] cycloaddition reactions affording these mentioned carbocycles the cycloaddition of allenoates and electron-deficient alkenes or imines catalysed by tertiary phosphanes, deserves to be described. ${ }^{80,81}$

This so called Lu's [3+2] cycloaddition ${ }^{82}$ is normally triggered by the phosphane attack to the $\beta$-carbon of the alkyl allenoate (or alkyl propiolates) generating a 1,3-dipole 161, which is an inner salt containing a phosphonium cation (Scheme 37). It was confirmed that the generation of the 1,3-dipole is the rate determining step. These zwitterionic species are ready to undergo 1,3-DC with the electrophilic alkane (the Michael-type addition step occurred by attack of the $\alpha$-position of the allyl anion 161 onto alkene) generating an intermediate betaine 162, which was transformed into the stabilised 


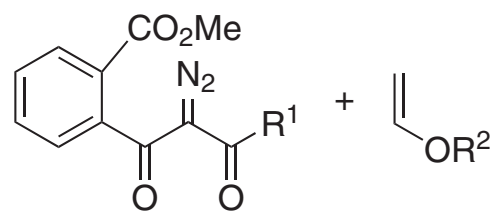

152

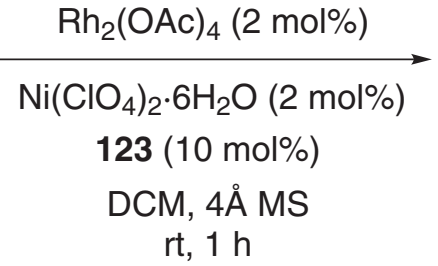

(78-96\%)<smiles>[R]O[C@H]1C[C@@]2(OC)OC1(C([2H])=O)C(=O)c1ccccc12</smiles>

endo-153

(77-97\% ee)<smiles>COC(=O)C1=C(C(=O)C=[NH2+])CCCC1</smiles>

154<smiles>COC12OC(C(=O)c3ccccc31)[C@@H]1CCO[C@@H]12</smiles>

155<smiles>CCCCC1C[C@@]2(OC)CCC(=O)C1O2</smiles>

156

(>99:1 endo:exo)

$(98 \%, 59 \%$ ee)

(88:12 exo:endo)

$(68 \%, 67 \%$ ee $)$

Scheme 36.

1,3-dipole after an internal [1,2]-prototropy shift. The final $\beta$-elimination regenerates the catalyst (chiral phosphane) and liberates the enantiomerically enriched carbocycle 159. In addition, if an imine is employed as dipolarophile a $\Delta^{3}$-pyrroline $\mathbf{1 6 0}$ is formed. All the mechanistic aspects of this reaction were supported by computational calculations and also demonstrated that this is a stepwise process. However, the initially postulated intramolecular [1,2]- or [1,3]-hydrogen shifts are impossible to occur owing to the existence of very high activation barriers.
The discovery of the beneficial effect of a small amount of water (traces) in the phosphane also supported this last hypothesis spite of performing the reactions under anhydrous conditions. ${ }^{81}$

The enantioselective version of this transformation has been attempted with chiral phosphanes shown in Figure 11, obtaining very good results of enantiomerically enriched polysubstituted cyclopentenes.

In the first catalytic enantioselective reaction, several chiral phosphanes were screened as catalysts and it

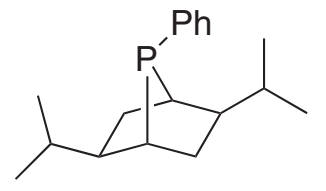

165<smiles>CC1(C)O[C@@H](Cc2ccccc2)[C@H](CPc2ccccc2)O1</smiles>

169<smiles>CC(C)(C)P1Cc2ccc3ccccc3c2-c2c(ccc3ccccc23)C1</smiles>

(R)-166

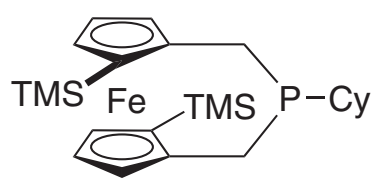

167<smiles>COC(=O)[C@H](CPc1ccccc1)NC(=O)c1ccccc1</smiles>

168<smiles>CC(C)CNC(=O)[C@H](C)NC(=S)NC(=S)N[C@H]1CCCC[C@@H]1Pc1ccccc1</smiles>

171

170

Figure 11. Chiral phosphanes acting as organocatalysts in the 1,3-DC of allenoates with electrophilic alkanes or imines. 
<smiles>C=CC(=O)O</smiles>

157<smiles>CC#CC(=O)O</smiles>

158

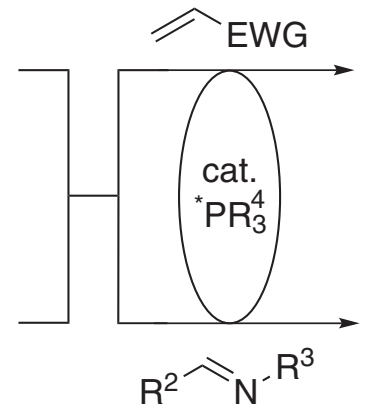

$\mathrm{R}^{1} \mathrm{O}_{2} \mathrm{C}$<smiles>[Mg]C1CC=CC1</smiles>

159<smiles>[R]OC(=O)C1=CCN([R])C1[R]</smiles>

160
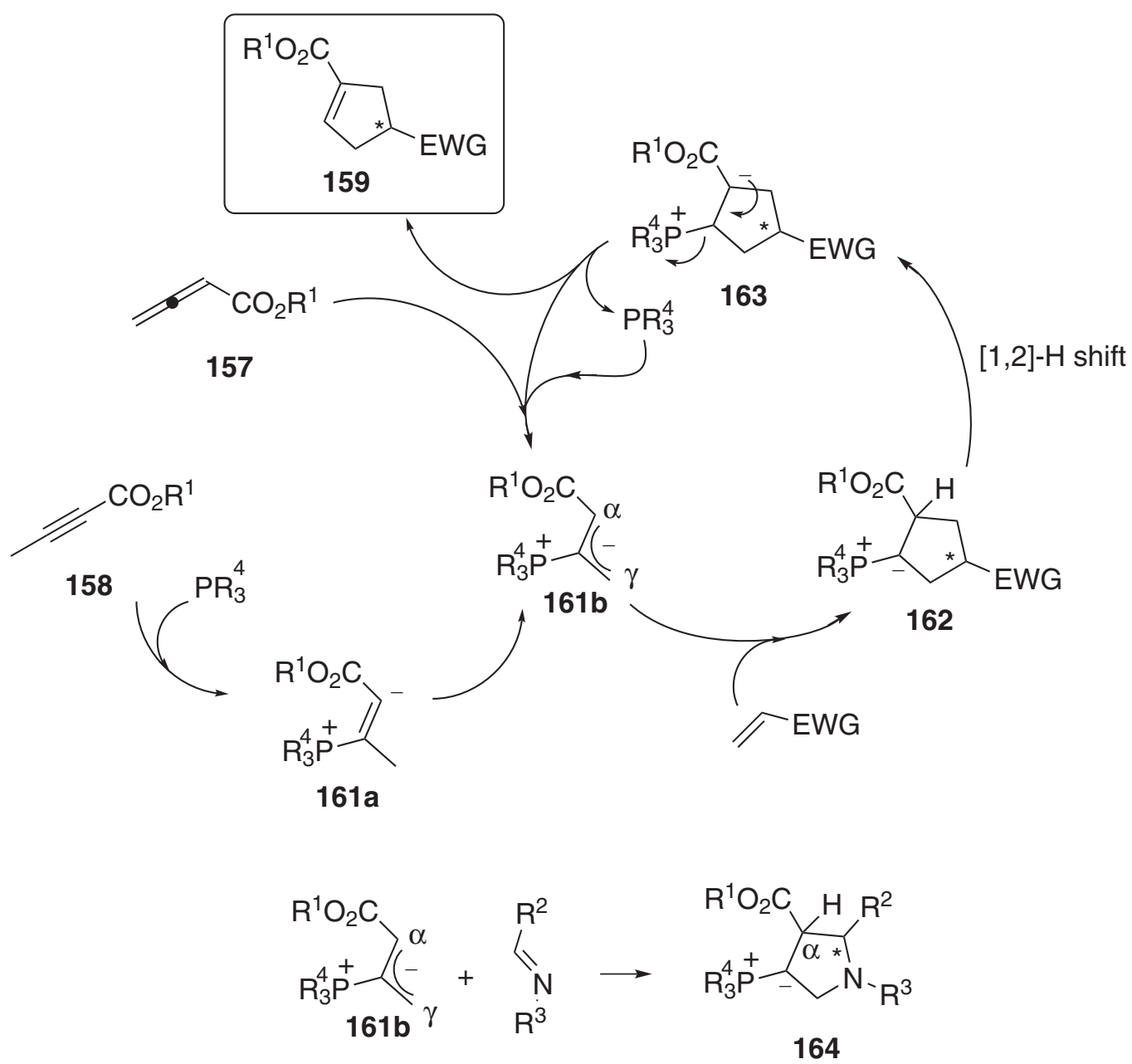

Scheme 37.

was observed that bicyclic phosphane 165 (Figure 11) (10 mol\%) afforded the best enantioselection (up to 93\% ee) and good chemical yields (up to $88 \%$ ), when the reaction of allenoates 157 and $\alpha, \beta$-unsaturated esters 172 was performed at $0{ }^{\circ} \mathrm{C}$ or room temperature. The major isolated product (up to $>99: 1$ ) was $\alpha-\mathbf{1 7 3}$ as result of the already mentioned attack of the intermediate allyl anion onto the electrophilic alkene through its $\alpha$-position (Scheme 38). ${ }^{83}$
Chiral phosphepine $(R)-\mathbf{1 6 6}(10 \mathrm{~mol} \%)$ (Figure 11) catalysed the asymmetric [3+2] cycloaddition of allene 157 with a wide array of enones (Scheme 39) ${ }^{84}$ It is worth noting that the opposite regioisomer $\gamma-\mathbf{1 7 6}$ (relative to the reaction done with acrylic esters shown in Scheme 38) was preferentially obtained in good chemical yields and good enantioselectivities (Scheme 39, reaction a). In addition, spirocyclic compounds, such as $\gamma$-179, was readily prepared from the reaction of $\mathbf{1 5 7}$ and $\mathbf{1 7 8}$ 
<smiles>[R7]C([R])=C[R14]([R])([H])[H]</smiles>

172

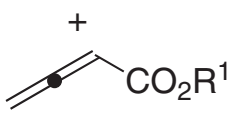

157

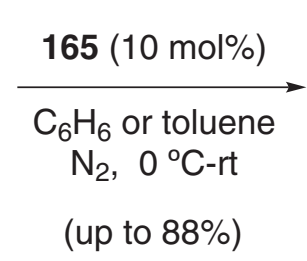

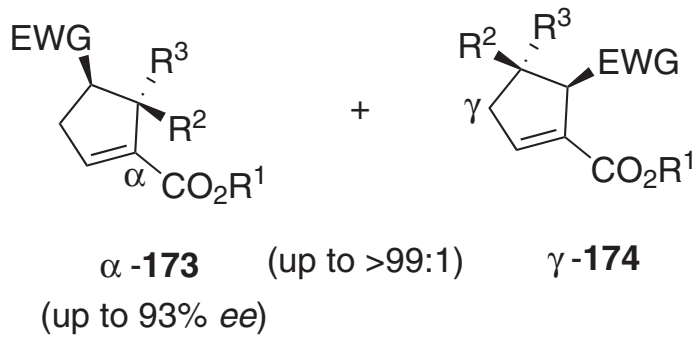

Scheme 38.

catalysed by $\left(R_{\mathrm{a}}\right) \mathbf{- 1 6 6}$, generating adjacent quaternary and tertiary stereocentres with a $95 \%$ ee in only one reaction step (Scheme 39, reaction b). ${ }^{84}$

An identical behavior was found when the reaction shown in reaction a of the Scheme 39, was performed under the modulation of chiral ferrocenyl phosphane 167 (10 mol\%, Figure 11). Cycloadducts $\boldsymbol{\gamma} \mathbf{- 1 7 6}$ were preferentially formed $(8: 1$ to $>20:<1)$ in good yields (up to $87 \%$ ) and slightly higher enantioselectivities than the results commented for Scheme 38. The synthesis of other spirocyclic systems similar to $\mathbf{1 7 9}$ was attempted obtaining, in general, very good yields and enantioselectivities $(88 \%$ and $80 \%$ ee $) .{ }^{85}$

As it was described above for Lewis acids, organocatalysts can also control the regioselectivity of the 1,3-DC. Although a chiral phosphane promoted the formation of the $\gamma$-adducts in the presence of $\alpha, \beta$-unsaturated ketones (chalcones), the (diphenylphosphino) methylglycine derivative 168 (10-100 mol\%, Figure 11) induced a completely opposite regiochemistry, favouring the generation of the cycloadduct $\alpha-\mathbf{1 8 1}$ at $-25^{\circ} \mathrm{C}$ in toluene in short reaction times (Scheme 40, reaction b). The $\alpha-\mathbf{1 8 1}$ and $\alpha \mathbf{- 1 8 4}$ products were obtained in good yields and high enantioselections (70-84\% ee, and 87-93\% ee, respectively) (Scheme 40). ${ }^{86}$ The analogous reactions catalysed by the Diop ligand 169 were not so successful because the enantioselections achieved of the major cycloadducts $\alpha-\mathbf{1 8 1}$ were modest (up to $77 \%$ ee $),{ }^{87}$ and never improved the previous results described in Scheme 40.

$N$-Tosyl arylimines were used as dipolarophiles trapping the reactive zwitterionic species $\mathbf{1 6 1 b}$, previously generated by the corresponding chiral phosphanes (Scheme 37). The intermediate betaine $\mathbf{1 6 4}$ underwent a stepwise protonation-deprotonation, followed by $\beta$-elimination to yield 3-pyrroline $\alpha-\mathbf{1 8 6}$ (Scheme 41). Although a large

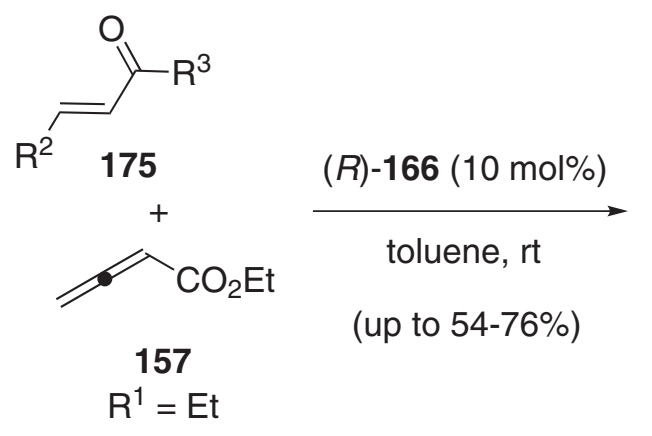<smiles>[R]C(=O)[C@H]1C(C(=O)OCC)=CC([Y])C1[R]</smiles>

(82-90\% ee) reaction a)<smiles>[R]C(=O)[C@H]1CC=C(C(=O)OCC)C1[R]</smiles>

(3:1 to $20: 1)$

$\alpha-177$

reaction b)<smiles>[R][R15](=[Se])C=CC(=O)OCC</smiles>

(R)-166 (10 mol\%)

toluene, rt

(57\%)<smiles>[Y]C1C=C(C(=O)OCC)[C@@]2(CCC/C(=C\c3ccccc3)C2=O)[C@H]1c1ccccc1</smiles>

$\gamma-179$

(95\% ee)

Scheme 39. 
<smiles>C=C1PCc2ccccc2C1=O</smiles>

180<smiles>C=CC(=O)OCc1ccccc1</smiles>

157

$$
\mathrm{R}^{1}=\mathrm{Bn}
$$

$168(10 \mathrm{~mol} \%)$

toluene, $-25^{\circ} \mathrm{C}, 3 \mathrm{~h}$

(53-95\%)<smiles>O=C(OCc1ccccc1)C1=CC[C@]2(CPCc3ccccc3C2=O)C1</smiles><smiles>O=C(OCc1ccccc1)C1=CCCC12CCc1ccccc1C2=O</smiles>

$$
\begin{array}{ll}
\alpha-181 \quad(\text { up to }>99: 1) & \gamma-182 \\
(70-84 \% \text { ee }) &
\end{array}
$$<smiles>CC=CC(=O)OCc1ccccc1</smiles>

$(89-96 \%)$<smiles>C[C@@H]1C=C(C(=O)OCc2ccccc2)[C@H](C(=O)Br)[C@H]1c1ccccc1</smiles>

$\alpha-184$

reaction $b$ )

$(87-93 \%$ ee $)$

Scheme 40.

number of chiral phosphanes were tested as catalysts, the chemical yields and enantioselections of $\alpha-\mathbf{1 8 6}(\mathrm{Z}=$ tosyl) were moderate (up to $84 \%$ and up to $61 \% e e$ ) when chiral organocatalyst $(R)$-166 was employed in $10 \mathrm{~mol} \%$ loading (Scheme 41) ${ }^{88,89}$ A higher enantioselection was achieved when $N$-diphenylphosphinoyl (DPP) imines 185 (Z = DPP) were employed as dipolarophiles using chiral phosphane (S)-166 (10 mol\%, Figure 11) as catalyst. Chemical yields were lower than those for the corresponding reaction carried out with $N$-tosylimines but the enantioselections were very high (up to $92 \%$ ee) (Scheme 41). ${ }^{90}$
Enantiopure rhenium-containing phosphane $\mathbf{1 7 0}$ (20 mol\%, Figure 11) was a promising catalyst for the enantioselective synthesis of heterocycles $\mathbf{1 8 6} .{ }^{91}$ Good to moderate enantioselections (51-60\% ee) and high yields (90-93\%) were obtained when the reaction occurred at $-30{ }^{\circ} \mathrm{C}$ in DCM for 8 days (Scheme 41 ).

Phosphano-thiourea catalyst 171 (10-20 mol\%, Figure 11) induced an excellent enantioselection in the 1,3-DC of $N$-DPP-imines and allenoate $157\left(\mathrm{R}^{1}=\mathrm{Et}\right)$. The reaction took place in toluene at $-30{ }^{\circ} \mathrm{C}$ and in the presence of water $(20 \mathrm{~mol} \%)$ and $\mathrm{Et}_{3} \mathrm{~N}(5 \mathrm{~mol} \%)$ in $48 \mathrm{~h}$.

$\begin{array}{llll}Z & \text { Chiral phosphine } \\ (10-20 \mathrm{~mol} \%)\end{array}$


The chemical yields were good $(68-90 \%)$ and the range of enantioselections was $94-98 \%$ ee (Scheme 41). It was likely that $\mathrm{H}_{2} \mathrm{O}$ (consistent with the stepwise [3+2] mechanism explained previously) effected protonation of the basic ylide intermediate $\mathbf{1 6 4}$ (Scheme 37) to form a pentavalent hydroxyphosphorane intermediate. The role of $\mathrm{Et}_{3} \mathrm{~N}$ is to promote the $\beta$-elimination and the liberation of the phosphane catalyst. The authors proposed an initial interaction of the thiourea moiety with the phosphanoyl group. Secondary interactions ( $\pi-\pi$ stacking or $\mathrm{C}=\mathrm{O} \cdots \mathrm{Ar}$ ) between the amide portion of the catalyst and the benzhydryl group of the imine could also provide additional selective stabilisation of the lowest energy transition state..$^{92}$

\section{Conclusions}

The enantioselective 1,3-DC is of considerable interest in diversity oriented synthesis (DOS) $)^{93}$ because its stereospecificity enables stereochemical diversification of up to four tetrahedral centres on different five membered carbo- or heterocycles. The generation of this stereogenic centres occurs in only one reaction step, but the optimisation of the reaction conditions is a very difficult task. There are multiple parameters to control with the aim to achieve the maximun levels of selectivity. In addition, a minimal modification or change in structures, ligands, solvent, additives, temperature, anion, cation etc., can cause a dramatic change in regio-, diastereo- or enantioselectivity of the process. The wider scope procedures corresponded to the Lewis acid promoted 1,3-DC using azomethine ylides and, to a lesser extent, nitrones.

Broad scopes, recovery of the catalyst and catalyst loadings are the three drawbacks to overcome by organocatalytic processes, whilst the recovery of the catalytic chiral metal complex has been scarcely documented and covering a narrow scope with structural limitations.

Organocatalysed and Lewis acid-catalysed 1,3-DC are two complementary and necessary tools in current asymmetric synthesis. The metal catalyst promoted $1,3-\mathrm{DC}$ is much more studied than the corresponding reactions mediated by organocatalysts, but enormous efforts are directed in improvements on the efficiency of both type of catalysts.

\section{Acknowledgments}

This work has been supported by the DGES of the Spanish Ministerio de Educación y Ciencia (MEC) (Consolider INGENIO 2010 CSD2007-00006, CTQ200762771/BQU, CTQ2007-65218/BQU and the HispanoBrazilian project PHB2008-0037-PC), the Generalitat
Valenciana (PROMETEO/2009/039), and the University of Alicante (GITE9020).

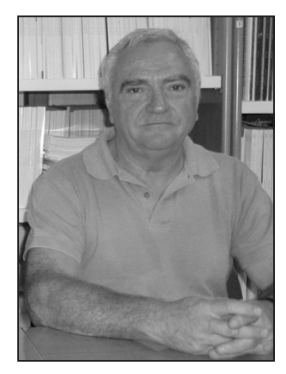

Miguel Yus (right) was born in Zaragoza (Spain) in 1947, and received his BSc (1969), MSc (1971) and PhD (1973) degrees from the University of Zaragoza. After spending two years as a postdoctoral fellow at the Max Planck Institut für Kohlenforschung in Mülheim a.d. Ruhr he returned to Spain to the University of Oviedo where he became associate professor in 1977, being promoted to full professor in 1987 at the same university. In 1988 he moved to a chair in Organic Chemistry at the University of Alicante where he is currently the head of the Organic Synthesis Institute (ISO). Professor Yus has been visiting professor at different institutions and universities such as ETH-Zentrum, Oxford, Harvard, Uppsala, Marseille, Tucson, Okayama, Paris, Strasbourg and Tokyo. He is co-author of more than 450 papers mainly in the field of the development of new methodologies involving organometallic intermediates. His current research interest is focused on the preparation of very reactive functionalized organometallic compounds and their use in synthetic organic chemistry, arene-catalyzed activation of different metals and preparation of new metal-based catalysts for homogeneous and heterogeneous selective reactions. Among others, he has received the Spanish-French Prize (1999), twice the Japan Society for the Promotion of Science Prize $(2000,2007)$ and the Stiefvater Memorial Lectureship Award (2001).

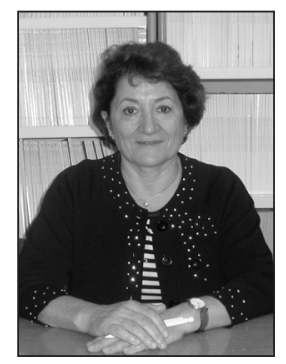

Carmen Nájera obtained her BSC at the University of Zaragoza in 1973 and her PhD at the University of Oviedo with J. Barluenga and M. Yus in 1979. She performed postdoctoral work at the ETH (Zurich) with D. Seebach, at the Dyson Perrins Laboratory (Oxford) with J. E. Baldwin, at Harvard University with E. J. Corey, and at Uppsala University with J.-E. Bäckvall. She was promoted to Associate Professor in 1985 at the University of Oviedo and Full Professor in 1993 at the University of Alicante. She has held visiting Professorships at the University of Arizona in Tucson (USA), Universidad Nacional del Sur in Bahía Blanca (Argentina), Louis Pasteur University in Strasbourg (France), and Ecole Nationale Superiéure de Chimie de Paris (France). She is coauthor of ca. 200 papers and 30 
reviews and has supervised the work of 23 PhD students. She was awarded with the "2006 Janssen Cilag Organic Chemistry Price" from the Spanish Royal Chemical Society of Chemistry and "2006 Rosalind Franklin International Lectureship" from the English Royal Society. Co-founder of a new chemical company MEDALCHEMY, S. L. as a spin-off of the University of Alicante. Her current research interest focused on sulfones, amino acids, asymmetric catalysis and palladium catalysis.

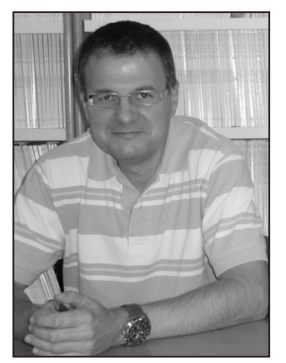

José Miguel Sansano was born in Rojales (Alicante), Spain in 1965. He studied chemistry at the University of Alicante where he obtained his BSc and PhD degrees in 1988 and 1994, respectively. After spending a two years postdoctoral stay at the University of Leeds (UK) with Prof. R. Grigg he joined the University of Alicante in 1996, where he was appointed Associate Professor in 2001. Co-founder of a new chemical company MEDALCHEMY, S. L. as a spin-off of the University of Alicante. His current research interests include asymmetric synthesis, sulfones, amino acids, and organometallic chemistry.

\section{References}

1. Mikami, K.; Lautens, M. eds.; New Frontiers on Asymmetric Catalysis, John Wiley \& Sons: New Jersey, 2007; Jacobsen, E. N.; Pfaltz, A.; Yamamoto, H. eds.; Comprehensive Asymmetric Catalysis, Vol., 1-3, Supplements 1-2, Springer-Verlag: Heidelberg, 2004.

2. Kobayashi, S.; Jørgensen, K. A. eds.; Cycloaddition Reactions in Organic Synthesis, Wiley-VCH: Weinheim, 2002.

3. For reviews dealing with general 1,3-dipolar cycloadditions, see: Kanemasa, S.; Synlett 2002, 1371; Padwa, A.; Pearson, W. H. eds.; Synthetic Applications of 1,3-Dipolar Cycloaddition Chemistry Towards Heterocycles and Natural Products, John Wiley \& Sons: New Jersey, 2003; Nair, V.; Suja, T. D.; Tetrahedron, 2007, 63, 12247; Padwa, A.; Bur, S. K.; Tetrahedron 2007, 63, 5341; Pellissier, H.; Tetrahedron 2007, 63, 3235 .

4. Sankararaman, S.; Pericyclic Reactions-A Textbook, WileyVCH: Weinheim, 2005; Fleming, I.; Frontier Orbitals and Organic Chemical Reactions, John Wiley \& Sons: Chichester, 2002.

5. For general reviews of 1,3-DC using azomethine ylides, see: Nájera, C.; Sansano, J. M.; Curr. Org. Chem. 2003, 7, 1105; Eberbach, W.; Sci. Synth. 2004, 27, 441; Coldham, I.; Hufton, R.; Chem. Rev. 2005, 105, 2765; Nájera, C.; Sansano, J. M.; Angew. Chem. Int. Ed. 2005, 44, 6272; Husinec, S.; Savic, V.;
Tetrahedron: Asymmetry 2005, 16, 2047; Pinho e Melo, T. M. V. D.; Eur. J. Org. Chem. 2006, 2873; Bonin, M.; Chauveau, A.; Micouin, L.; Synlett 2006, 2349; Pandey, G.; Banerjee, P.; Gadre, S. R.; Chem. Rev. 2006, 106, 4484; Nájera, C.; Sansano, J. M. In Topics Heterocyclic Chem., Hassner, A. ed.; 2008, 12, 117; Stanley, L. M.; Sibi, M. P.; Chem. Rev. 2008, 108, 2887; Álvarez-Corral, M.; Muñoz-Dorado, M.; Rodríguez-García, I.; Chem. Rev. 2008, 108, 3174; Naodovic, M.; Yamamoto, H.; Chem. Rev. 2008, 108, 3132.

6. Karoyan, P.; Sagan, S.; Lequin, O.; Quancard, J.; Lavielle, S.; Chassaing G.; Targets Heterocycl. Syst. 2004, 8, 216; Nájera, C.; Sansano, J. M.; Chem. Rev. 2007, 107, 4273; Calaza, M. I.; Cativiela, C.; Eur. J. Org. Chem. 2008, 3427; Soloshonok, V. A.; Izawa, K. eds.; Asymmetric Synthesis and Applications of $\alpha$-Amino Acids, ACS publications: Washington, 2009.

7. Allway, P.; Grigg, R.; Tetrahedron Lett. 1991, 32, 5817.

8. Longmire, J. M.; Wang, B.; Zhang, X.; J. Am. Chem. Soc. 2002, 124, 13400.

9. Chen, C.; Li, X.; Schreiber, S. L.; J. Am. Chem. Soc. 2003, 125, 10174; Knöpfel, T. F.; Aschwanden, P.; Ichikawa, T.; Watanabe, T.; Carreira, E. M.; Angew. Chem. Int. Ed. 2004, 43, 5971; Zheng, W.; Zhou, Y.-G.; Org. Lett. 2005, 7, 5055; Stohler, R.; Wahl, F.; Pfaltz, A.; Synthesis 2005, 1431.

10. For copper(II)-catalysed 1,3-DC see: Oderaotoshi, Y.; Cheng, W.; Fujitomi, S.; Kasano, Y.; Minakata, S.; Komatsu, M.; Org. Lett. 2003, 5, 5043.

11. Zeng, W.; Zhou, Y-G.; Tetrahedron Lett. 2007, 48, 4619.

12. Zeng, W.; Chen, G.-Y.; Zhou, Y-G.; Li, Y.-X.; J. Am. Chem. Soc. 2007, 129, 750.

13. Nájera, C.; Retamosa, M. G.; Sansano, J. M.; Org. Lett. 2007, 9, 9025; Nájera, C.; Retamosa, M. G.; Sansano, J. M.; de Cózar, A.; Cossío, F. P.; Tetrahedron: Asymmetry 2008, 19, 2913.

14. Nájera, C.; Retamosa, M. G.; Sansano, J. M.; Angew.Chem. Int. Ed. 2008, 47, 6055; Nájera, C.; Retamosa, M. G.; Sansano, J. M.; de Cózar, A.; Cossío, F. P.; Eur. J. Org. Chem. 2009, DOI:10.1002/ EJOC.200900774.

15. Yu, S. B.; Hu, X.-P.; Deng, J.; Wang, D.-Y.; Duan, Z.-C.; Zheng, Z.; Tetrahedron: Asymmetry 2009, 20, 621.

16. Wang, C. J.; Xue, Z.-Y.; Liang, G.; Lu, Z.; Chem. Commun. 2009, 2905.

17. Gao, W.; Zhang, X.; Raghunath, M.; Org. Lett. 2005, 7, 4241.

18. Yan, X.-X.; Peng, Q.; Zhang, Y.; Zhang, K. ; Hong, W.; Hou, X.-L.; Wu, Y.-D.; Angew. Chem. Int. Ed. 2006, 45, 1979.

19. Cabrera, S.; Gómez-Arrayás, R.; Carretero, J. C.; J. Am. Chem. Soc. 2005, 127, 16394.

20. Cabrera, S.; Gómez-Arrayás, R.; Martín Matute, B.; Cossío, F. P.; Carretero, J. C.; Tetrahedron 2007, 63, 6587.

21. López-Pérez, A.; Adrio, J.; Carretero, J. C.; J. Am. Chem. Soc. 2008, 130, 10084.

22. Herández-Toribio, J.; Gómez- Arrayás, R.; Martín-Matute, B.; Carretero, J. C.; Org. Lett. 2009, 11, 393. 
23. LLamas, T.; Gómez-Arrayás, R.; Carretero, J. C.; Org. Lett. 2006, 8, 1795; Llamas, T.; Gómez-Arrayás, R.; Carretero, J. C.; Synthesis 2007, 950.

24. Martín-Matute, B.; Pereira, S. I.; Peña-Cabrera, E.; Adrio, J.; Silva, A. M. S.; Carretero, J. C.; Adv. Synth. Catal. 2007, 349 , 1714.

25. Shi, M.; Shi, J.-W.; Tetrahedron: Asymmetry 2007, 18, 645.

26. Fukuzawa, S.; Oki, H.; Org. Lett. 2008, 10, 1747.

27. Wang, C.-J.; Liang, G.; Xue, Z.-Y.; Gao, F.; J. Am. Chem. Soc. 2008, 130, 17250.

28. López-Pérez, A.; Adrio, J.; Carretero, J. C.; Angew. Chem. Int. Ed. 2009, 48, 340.

29. Dogan, O.; Koyuncu, H.; Garner, P.; Bulut, A.; Youngs, W. J.; Panzner, M.; Org. Lett. 2006, 8, 4687.

30. Saito, S.; Tsubogo, T.; Kobayashi, S.; J. Am. Chem. Soc. 2007, 29, 5364; Tsubogo, T.; Saito, S.; Seki, K.; Yamashita, Y.; Kobayashi, S.; J. Am. Chem. Soc. 2008, 130, 13321.

31. Gothelf, A. S.; Gothelf, K. V.; Hazell, R.-G.; Jørgensen, K. A.; Angew. Chem. Int. Ed. 2002, 41, 4236.

32. Melhado, A. D.; Luparia, M.; Toste, F. D.; J. Am. Chem. Soc. 2007, 129, 12638.

33. Shi, J.-W.; Zhao, M.-X.; Lei, Z.-Y.; Shi, M.; J. Org. Chem. 2008, 73, 305.

34. Dalko, P. I. ed.; Enantioselective Organocatalysis; WileyVCH: Weinheim, 2007; Berkessel A, Gröger H.; Asymmetric Organocatalysis; Wiley-VCH, Weinheim, 2005.

35. Alemparte, C.; Blay, G.; Jørgensen, K. A.; Org. Lett. 2005, 7, 4569.

36. Arai, S.; Takahasi, F.; Tsuji, R.; Nishida, A.; Heterocycles 2006 , $67,495$.

37. Vicario, J. L.; Reboredo, S.; Badía, D.; Carrillo, L.; Angew. Chem. Int. Ed. 2007, 48, 6252.

38. Ibrahem, I.; Ríos, R.; Vesely, J.; Córdova, A.; Tetrahedron Lett. 2007, 48, 6252 .

39. Xue, M.-X.; Zhang, X.-M.; Gong, L.-Z.; Synlett 2008, 691.

40. Kudryavtsev, K. V.; Zagulyaeva, A. A.; Rus. J. Chem. 2008, 44 , 378.

41. Chen, X.-H.; Zhang, W.-Q.; Gong, L.-Z.; J. Am. Chem. Soc. 2008, 130, 5652.

42. Xie, J.; Yoshida, K.; Takasu, K.; Takemoto, Y.; Tetrahedron Lett. 2008, 49, 6910.

43. Agbodjan, A. A.; Cooley, B. E.; Copley, R. C. B.; Corfield, J. A.; Flanagan, R. C.; Glover, B. N.; Guidetti, R.; Haigh, D.; Howes, P. D.; Jackson, M. M.; Matsuoka, R. T.; Medhurst, K. J.; Millar, A.; Sharp, M. J.; Slater, M. J.; Toczko, J. F.; Xie, S.; J. Org. Chem. 2008, 73, 3094; Flanagan, R. C.; Xie, S.; Millar, A.; Org. Process Res. Develop. 2008, 12, 1307.

44. Nájera, C.; Sansano, J. M.; Org. Biomol. Chem. 2009, DOI: 10.1039/b913066g.

45. Nájera, C.; Retamosa, M. G.; Sansano, J. M.; Spanish patent application: P200800908, 2008.
46. Nakano, M.; Terada, M.; Synlett 2009, 1670.

47. Revuelta, J.; Cicchi, S.; Goti, A.; Brandi, A.; Synthesis 2007, 485; Merino, P.; Science of Synthesis 2004, 27, 511.

48. Hyrosova, Y.; Fisera, L.; Medvecky, M.; Reissing, H.-U.; AlHarrasi, A.; Koos, M.; Arkivoc 2009, ix, 122; Grigor'ev, I. A.; In From Nitrile Oxides, Nitrones and Nitronates in Organic Synthesis; Feuer, H. ed.; 2nd ed., John Wiley \& Sons Inc.: New Jersey, 2008; Floyd, R. A.; Kopke, R. D.; Choi, C.-H.; Foster, S. B.; Doblas, S.; Towner, R. A.; Free Radic. Biol. Med. 2008, $45,1361$.

49. Cicchi, S.; Cordero, F. M.; Gioni, D.; Prog. Heterocycl. Chem. 2003, 15, 261.

50. Gothelf, K. V.; Jørgensen, K. A.; Acta Chem. Scand. 1996, 50, 652.

51. Carmona, D.; Lamata, M. P.; Viguri, F.; Ferrer, J.; García, N.; Lahoz, F. J.; Martín, M. L.; Oro, L. A.; Eur. J. Inorg. Chem. 2006, 3155.

52. Carmona, D.; Lamata, M. P.; Viguri, F.; Rodríguez, R.; Lahoz, F. J.; Oro, L. A.; Chem. Eur. J. 2007, 13, 9746; Carmona, D.; Lamata, M. P.; Viguri, F.; Rodríguez, R.; Fischer, T.; Lahoz, F. J.; Dobrinovitch, I. T.; Oro, L. A.; Adv. Synth. Catal. 2007, 349, 1751; Carmona, D.; Lamata, M. P.; Viguri, F.; Rodríguez, R.; Lahoz, F. J.; Fabra, M. J.; Oro, L. A.; Tetrahedron: Asymmetry 2009, 20, 1197.

53. Ding, X.; Taniguchi, K.; Hamamoto, Y.; Sada, K.; Fujinami, S.; Ukaji, Y.; Inomata, K.; Bull. Chem. Soc. Jpn. 2006, 79, 1069.

54. Hashimoto, T.; Omote, M.; Kano, T.; Maruoka, K.; Org. Lett. 2007, 9, 4805; Hashimoto, T.; Omote, M.; Maruoka, K.; Org. Biomol. Chem. 2008, 6, 2263; Hashimoto, T.; Omote, M.; Hato, Y.; Kano, T.; Maruoka, K.; Chem. Asian J. 2008, 3, 407.

55. Zu, Y.-K.; Liu, B.; You, J.; Wang, Y.-X.; J. Chem. Res. 2007, 662.

56. Wang, Y.-X.; Zhu, Y.-K.; Liu, B.; You, J.; Liu, N.; J. Chem. Res. 2007, 83.

57. Wang, Y.; Wolf, J.; Zavalij, P.; Doyle, M. P.; Angew. Chem. Int. Ed. 2008, 47, 1439.

58. Lim, K. C.; Hong, Y.-T.; Kim, S.; Adv. Synth. Catal. 2008, 350, 380 .

59. Phomkeona, K.; Takemoto, T.; Ishima, Y.; Shibatomi, K.; Iwasa, S.; Nishiyama, H.; Tetrahedron 2008, 64, 1813.

60. Badoin, A.; Brinkmann, Y.; Viton, F.; Kündig, E. P.; Pure Appl. Chem. 2008, 80, 1013; Badoin, A.; Bernardinelli, G., Mareda, J.; Kündig, E. P.; Viton, F.; Chem. Asian J. 2008, 3, 1298.

61. Du, W.; Liu, Y.-K.; Yue, L.; Chen, Y.-C.; Synlett 2008, 2997.

62. Jiao, P.; Nakashima, D.; Yamamoto, H.; Angew. Chem. Int. Ed. 2008, 47, 2411.

63. Chow, S. S.; Nevalainen, M.; Evans, C. A.; Johanes, C. W.; Tetrahedron Lett. 2007, 48, 277.

64. Weselinski, L.; Stepniak, P.; Jurczak, J.; Synlett 2009, 2261.

65. Sibi, M. P.; Itoh, K.; Jasperse, C. P.; J. Am. Chem. Soc. 2004, 126,5366 . 
66. Serizawa, M.; Ukaji, Y.; Inomata, K.; Tetrahedron: Asymmetry 2006, 17, 3075.

67. Yamamoto, H.; Hayashi, S.; Kubo, M.; Harada, M.; Hasegawa, M.; Noguchi, M.; Sumimoto, M.; Hori, K.; Eur. J. Org. Chem. 2007, 2859.

68. Brinkmann, Y.; Madhushaw, R. J.; Jazzar, R.; Bernardinelli, G.; Kündig, E. P.; Tetrahedron 2007, 63, 8413.

69. Gucma, M.; Golebiewski, W. M.; J. Heterocycl. Chem. 2008, $45,241$.

70. Golebiewski, W. M.; Gucma, M.; J. Heterocycl. Chem. 2008 , $45,1687$.

71. Suga, H.; Adachi, Y.; Fujimoto, K.; Furihata, Y.; Tsuchida, T.; Kakehi, A.; Baba, T.; J. Org. Chem. 2009, 74, 1099.

72. Ono, F.; Ohta, Y.; Hasegawa, M.; Kanemasa, S.; Tetrahedron Lett. 2009, 50, 2111.

73. Kano, T.; Hashimoto, T.; Maruoka, K.; J. Am. Chem. Soc. 2006, 128, 2174.

74. Sibi, M. P.; Stanley, L. M.; Soeta, T.; Org. Lett. 2007, 9, 1553.

75. Tsutsui, H.; Shimada, N.; Abe, T.; Anada, M.; Nakajima, M.; Nakamura, S.; Nambu, H.; Hashimoto, S.; Adv. Synth. Catal. 2007, 349, 521;

76. Shimada, N.; Anada, M.; Nakamura, S.; Nambu, H.; Tsutsui, H.; Hashimoto, S.; Org. Lett. 2008, 10, 3603;

77. Nambu, H.; Hikime, M.; Krishnamurthi, J.; Kamiya, M.; Shimada, N.; Hashimoto, S.; Tetrahedron Lett. 2009, 50, 3675.

78. Hodgson, D. M.; Glen, R.; Redgrave, A. J.; Tetrahedron: Asymmetry 2009, 20, 754.
79. Suga, H.; Ishimoto, D.; Higuchi, S.; Ohtsuda, M.; Arikawa, T.; Tsuchida, T.; Kakehi, A.; Baba, T.; Org. Lett. 2007, 9, 4359.

80. Methot, J. L.; Roush, W. R.; Adv. Synth. Catal. 2004, 346, 1035 ; Nair, V.; Menon, R. S.; Sreekanth, A. R.; Abhilash, N.; Bijn, A. T.; Acc. Chem. Res. 2006, 39, 520.

81. Liang, Y.; Liu, S.; Xia, S.; Li, X.; Yu, Z.-X. ; Chem. Eur. J. 2008, 14, 4361.

82. Zhang, G.; Lu, X.; J. Org. Chem. 1995, 60, 2906.

83. Zhu, G.; Chen, Z.; Jiang, Q.; Xiao, D.; Cao, P.; Zhang, X.; J. Am. Chem. Soc. 1997, 119, 3836.

84. Wilson, J. E.; Fu, G.; Angew. Chem. Int. Ed. 2006, 45, 1426.

85. Voituriez, A.; Panossian, A.; Fleury-Brégeot, N.; Retailleau, P.; Marinetti, A.; J. Am. Chem. Soc. 2008, 130, 14030.

86. Cowen, B. J.; Miller, S. J.; J. Am. Chem. Soc. 2007, 129, 10988.

87. Wallace, D. J.; Sidda, R. L.; Reamer, R. A.; J. Org. Chem. 2007, 72, 1051.

88. Jean, L.; Marinetti, A.; Tetrahedron Lett. 2006, 47, 2141;

89. Fleury-Brégeot, N.; Jean, L.; Retailleau, P.; Marinetti, A.; Tetrahedron 2007, 63, 11920;

90. Pinto, N. ; Fleury-Brégeot, N.; Marinetti, A.; Eur. J. Org. Chem. 2009, 146.

91. Scherer, A.; Gladysz, J. A.; Tetrahedron Lett. 2006, 47, 6335.

92. Fang, Y.-Q.; Jacobsen, E. N.; J. Am. Chem. Soc. 2008, 130, 5660.

93. Schreiber, S. L.; Science 2000, 287, 1964.

Received: October 1, 2009 Web Release Date: February 1, 2010 